\title{
NBSIR 88-3742
}

\section{Certification of SRM 1879 Respirable Cristobalite As A Quantitative X-Ray Diffraction SRM}

Madeline A. Kuchinski, Camden R. Hubbard and Carl Robbins

U.S. DEPARTMENT OF COMMERCE

National Bureau of Standards

Ceramics Division

Gaithersburg, MD 20899 -

April 1988
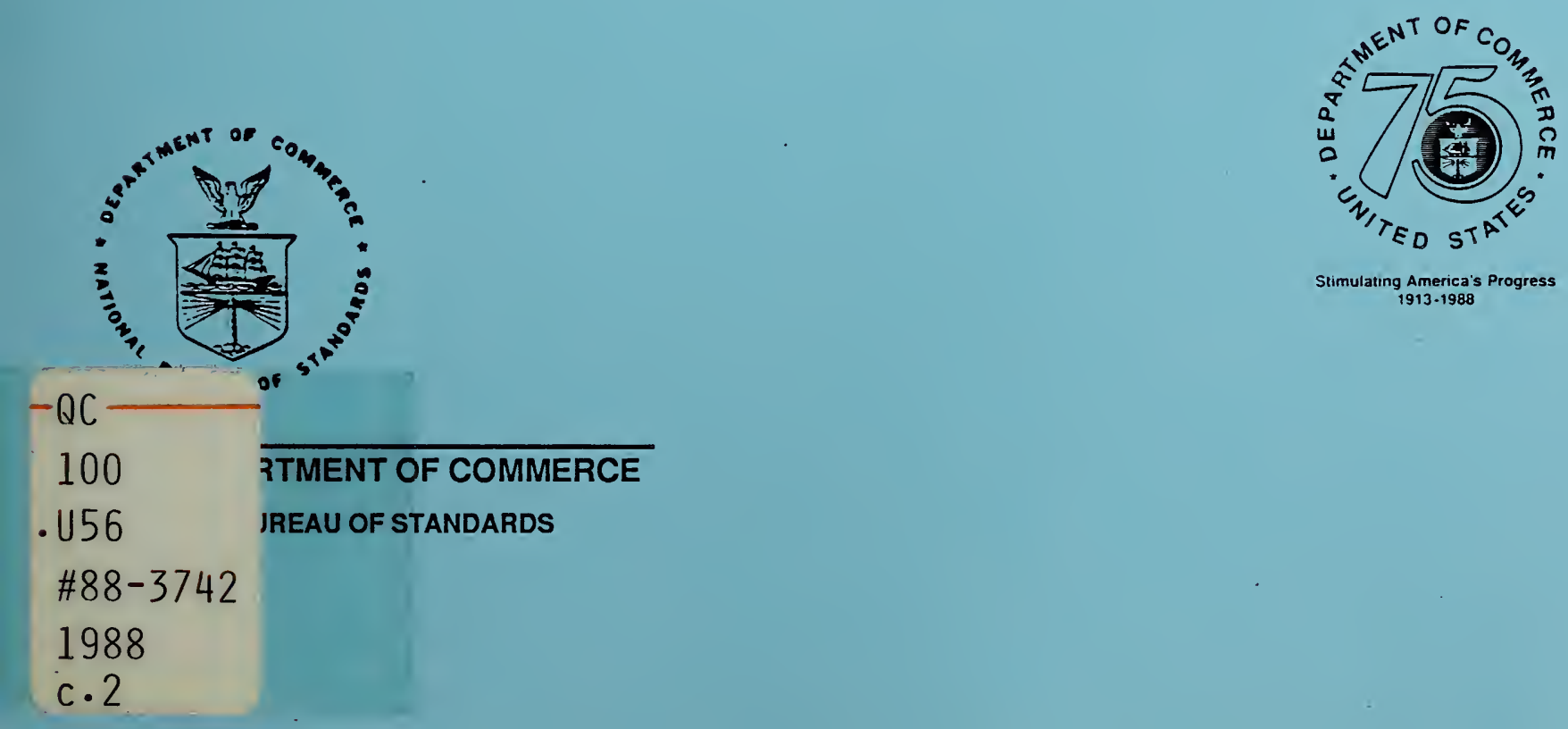

Stimulating America's Progress 1913-1988 



\section{CERTIFICATION OF SRM 1879 RESPIRABLE CRISTOBALITE AS A QUANTITATIVE X-RAY DIFFRACTION SRM}

Madeline A. Kuchinski, Camden R. Hubbard and Carl Robbins

U.S. DEPARTMENT OF COMMERCE National Bureau of Standards Ceramics Division

Gaithersburg, MD 20899

April 1988

U.S. DEPARTMENT OF COMMERCE, C. William Verity, Secretary NATIONAL BUREAU OF STANDARDS, Ernest Ambler, Director 



\title{
NBS INTERNAL REPORT
}

\section{CERTIFICATION OF SRY 1879 RESPIRABLE CRISTOBALITE AS A QUANTITATIVE X-RAY DIFFRACTION SRM}

\author{
Madeline A. Kuchinski \\ Camden R. Hubbard \\ Carl Robbins \\ National Bureau of Standards \\ Institute for Materials Science \& Engineering \\ Ceramics Division \\ Gaithersburg, MD 20899
}

\begin{abstract}
Well characterized, highly crystalline standard materials are essential for accurate quantitative $x$-ray powder diffraction work. Synthetic cristobalite powder was certified as a Standard Reference Material for quantitative $\mathrm{x}$-ray diffraction analysis of cristobalite content. Qualitative analyses of the bulk powder by Guinier de Wolff camera and focusing diffractometer indicated only crystalline $\alpha$ - cristobalite. Elemental analysis revealed only trace impurities; the largest being aluminum at $1000 \mathrm{ppm}$. Quantitative determination of the crystallinity of the material was performed. A quantitative technique which employs a modified method of additions to directly analyze for low amorphous content in crystalline matrices was developed and tested. For this method, known amounts of amorphous material are added to the starting powder ("spiking"). The method uses the ratio of a measure of the intensity of the amorphous phase to the intensity of a reference line from a crystalline phase. A critical step of the method is to correctly establish the background intensity. A completely crystalline material of similar scattering power was used to establish background intensity. An amorphous phase close in composition to the amorphous phase existing in the analyte was used for spiking. The certified crystalline purity of the cristobalite SRM 1879 was 98.0 weight percent crystalline cristobalite. The estimated standard deviation was 1.0 weight percent arising from a standard deviation of 0.5 weight percent due to random and inhomogeneity errors plus an estimated likely systematic error of 0.5 weight percent.
\end{abstract}


TABLE OF CONTENTS

ABSTRACT

LIST OF TABLES

3

LIST OF FIGURES

5

INTRODUCTION

LITERATURE REVIEW

7

THEORY OF METHOD OF ADDITIONS

EXPERTMENTAL CONSIDERATIONS

MATERIALS AND EXPERIMENTAL PROCEDURE

RESULTS

DISCUSSION: Tests for Homogeneity

DISCUSSION: Analysis of Amorphous Content

CONCLUSION

REFERENCES 
Table 1. Chemical Analysis of As-Received Cristobalite by

D.C. Arc Emission Spectroscopy

Table 2. Equivalent Spherical Diameters of Cristobalite

Measured Using An X-Ray Sedigraph Technique

Table 3. Internal Standard Peak Positions used to Determine the Polynomial Correction for the Cristobalite Reflections Corresponding to Sample 211 from Table 6, Run 2

Table 4. Observed, Corrected and Calculated $2 \theta$ and D-spacing

Table 5. Lattice Parameters Measured from 16 Randomly

Selected Bottles, Procedure as outlined in Powder Diffraction

with $W$ and FP as two theta calibration standards

Table 6. Lattice Parameters Test A (B\#211) - Sample Mounted

Once, Removed \& Reinserted for Three Runs in Diffractometer

Table 7. Lattice Parameters Test B (B\#211) - Sample Mounted

Once, Three Consecutive X-Ray Runs Without Removing Sample

Table 8. Lattice Parameters. Test C (B\#211) - Sample Remounted

Between Each of Three X-Ray Analyses

Table 9. Lattice Parameters Test D (B\#211) - Three Mixtures,

Same Bottle, One X-Ray Analysis Each

Table 10. Relative Intensity Data - Cristobalite

Table 11. Reference Intensity Ratio - $\left\langle\operatorname{RIR}_{\mathrm{Cr}}\right.$ is, $\left.\mathrm{Cr}_{2} \mathrm{O}_{3}\right\rangle$

measured using experimentally determined $I^{t} I_{\text {values }}$

for that bottle

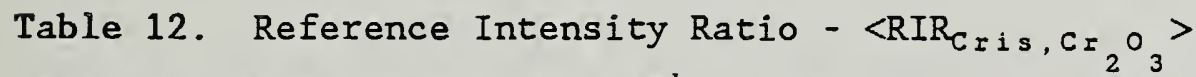
measured using the average $I^{I \theta I}$ values input from Table 10

Table 13. Amorphous Content in Cristobalite Determined by

Modified Method of Additions, Using Ground Quartz for.

Background Approximation

Table 14. Amorphous Weight Fraction and RIR Constant of Acid Washed Samples 126 and 187

Table 15. Relative Intensity Data - Test for Preferred 
Table 16. Input Data for POWD12 - Calculated Patterns of Cristobalite and $\mathrm{Cr}_{2} \mathrm{O}_{3}$

Table 17. Relative Intensity Data from Table 10 Converted to $I^{R \otimes 1}(102)=100$ Scale

Table 18. Relative Intensity Data from RIR Measurement Converted to $I^{R e 1}(102)=100$ Scale.

Table 19. Estimated Errors for Analysis of Sample 126

Table 20. Results of the Amorphous Content Determination

for Samples 92 and 304 using Three and Four Spiked Samples

Table 21. Amorphous Content of Cristobalite Determined

by the Modified Method of Additions, Using Silicon

(SRM 640a) for the Background Approximation

Table 22. Results of the Method of Additions for Determination of the Amorphous Silica Content in Cristobalite Samples 126 and 304 Using Modified Background Intensity

Table 23. Results of the Method of Additions for Determination of the Amorphous Silica Content in Cristobalite Samples 126 and 304 Using Modified Background Intensity

Table 24. Results of. the Modified Method of Additions for Determination of the Amorphous Silica Content in Cristobalite Samples 211 and 304 using Redefined Area 3

Table 25. Results of the Modified Method of Additions for Determination of the Amorphous Silica Content in Cristobalite Sample 304, Using Silica Gel as Diluent, Four Spiked Samples and Redefined Area 3 


\section{LIST OF FIGURES}

Page

Figure 1. Amorphous Regions and Reference Lines used in

Glass Phase Quantitative Analysis of Quartz.

Figure 2. X-Ray Diffraction Pattern of Cristobalite from

0 to 90 Degrees Two-Theta.

Figure 3. X-Ray Diffraction Pattern of Cristobalite Sample

10 Mixed with Tungsten for High Angle Calibration and

Fluorophlogopite for Low Angle Calibration.

Figure 4. Lattice Constant a (in $\dot{A}$ ) versus Weight Percent

Amorphous for 8 Samples of Cristobalite. Error bars indicate $2 \sigma$.

Figure 5. Lattice Constant c (in $\dot{A}$ ) versus Weight Percent Amorphous for 8 Samples of Cristobalite. Error bars indicate $2 \sigma$.

Figure 6. Scanning Electron Micrographs of Cristobalite

Sample 211 at Magnifications of 2000X and 5000X.

Figure 7. Weight Percent Amorphous versus RIR Constant for

8 Samples of Cristobalite. Error bars indicate $2 \sigma$.

Figure 8. $I_{i \alpha} / I_{j \beta}$ versus Grams of Analyte Added per Gram of Original Material for Amorphous Content Determination in Cristobalite Sample 126.

Figure 9. Amorphous Regions and Reference Lines used in

Amorphous Phase Quantitative Analysis of Cristobalite.

Figure 10. Measured Intensities of Amorphous Areas and

Reference Lines for Sample 211.

Figure 11. X-Ray Diffraction Pattern of Cristobalite Sample 


\section{INTRODUCTION}

Respirable dusts in the work place have long presented health hazards to industrial workers. X-Ray diffraction methods have been widely adopted to quantify the amounts of crystalline phases in the dusts. These methods, however, require crystalline standards. Recently the National Institute of Occupational Safety and Health (NIOSH) published regulations for testing of respirable dusts which require standards of quartz and its polymorphs ${ }^{1}$.

The Standard Reference Material 1878, Respirable Quartz, was certified as a quantitative $x$-ray powder diffraction standard to serve as a standard for testing of respirable silica as well as providing a standard material for analysis of crystalline quartz in ceramic materials. A modified method of additions was chosen to directly determine the amorphous content of the quartz SRM and, by difference, the crystallinity.

In quantitative $\mathrm{x}$-ray diffraction the most common method for crystalline phase analysis is the internal standard method. The premise is that a material whose crystallinity is "known" is used as a standard; uncertainty in the crystallinity of the standard results in a corresponding uncertainty in the analysis. Thus a cristobalite powder, certified as to crystallinity is needed as an internal standard for accurate quantitative $\mathrm{x}$-ray diffraction analysis. Here cristobalite may be used as a qualitative standard material as well as a SRM for quantitative analysis.

Respirable cristobalite is the second in the series of $\mathrm{SiO}_{2}$ standards intended for use as a calibration standard for quantitative analysis by $x-$ ray diffraction methods. Cristobalite was chosen.as a standard reference material. (SRM 1879) for quantitative $x$-ray powder diffraction for several reasons. In particular, cristobalite is required as a health and safety standard for analysis of respirable cristobalite by XRD methods according to NIOSH Analytical P \& CAM 259 ${ }^{1}$. This (and equivalent methods) is also useful for quantitative analysis of cristobalite in silica-containing ceramics such as refractory brick and glass ceramics. Due to its anisotropic coefficient of thermal expansion, modest concentrations of cristobalite can cause failure due to thermal cycling induced fracture. The need for a sensitive technique for the direct determination of amorphous content arises because of the importance of glassy phases in ceramics. Glassy grain boundaries in ceramic compacts may arise from amorphous content in the starting materials. Many ceramic reinforcements, fiber and whisker alike, may contain glassy phases which influence their intrinsic properties and interactions in composite materials. The properties and structural performance of glass-ceramics and partially devitrified glasses are controlled by the composition and amount of amorphous phase.

Cristobalite also presents a second "model" system for testing of the modified method of additions technique developed during certification of SRM 1878, Respirable Quartz, for the direct determination of amorphous silica in crystalline matrices. This synthetic cristobalite is useful as a model because it is single phase, highly crystalline, and contains only amorphous silica. However, "pure" cristobalite in either single crystal or polycrystalline form is not as common in nature as is quartz. Therefore, establishing the background intensity for cristobalite becomes a greater problem than for quartz. Cristobalite is a natural progression in 
complexity from the quartz model. Thus in certifying cristobalite as a quantitative $x$-ray diffraction SRM, the modified method of additions for direct analysis of amorphous content was tested.

This report is concerned with the extension and further validation of the modified method of additions adopted for the quartz certification. All the data collected for the synthetic cristobalite certified in this study, will be presented. These include qualitative analysis for phase homogeneity and sample purity, quantitative analysis for direct determination of the amorphous silica content in cristobalite and methods to evaluate the accuracy of the modified additions method.

\section{LITERATURE SEARCH}

Since the early $1950^{\prime} \mathrm{s}$, polymer scientists have developed and tested absolute and relative methods for determining the crystalinity of polymers. The advent of automated $x$-ray diffraction and computer refinement of data have spurred ceramists to adopt and tailor these methods to complex ceramic systems. Until recently, amorphous content has been determined indirectly by known quantitative $x$-ray diffraction techniques. Chung $^{2}$ and Knudsen ${ }^{3}$ identified crystalline phases and quantified these phases utilizing an internal standard method. Mass balance and subtraction from $100 \%$ yields the weight percent amorphous. Large uncertainties in the weight percent amorphous are common problems of this approach. Relative methods for rating the crystallinity of polymers were adapted by OhIberg and Strickler ${ }^{4}$ to a glass-ceramic system, however the need for an absolute measurement technique still remained. Cervinka and Dusil ${ }^{5}$ determined the amorphous content in partially devitrified glasses by measuring the intensity in a two-theta region where the intensity was due solely to the amorphous component and background scattering. The background intensity was estimated by the measured background component of a mixture of crystalline oxides in the same proportion as used for preparation of the parent glass. Three samples varying in degree of crystallinity were prepared from the same melt and compared to the parent glass. The degree of crystallinity was determined for each step within the interval of measurement. Torii ${ }^{6}$ et al., devised a two-point background method for determining the amorphous content in natural zeolites containing iron. No exact mention is made of how they corrected for the diffuse scattering contribution to the background under the amorphous intensity. However the authors used a mixture of the crystalline phases present in the rocks as a standard and monitored the influence of amorphous additions as well as ferric oxide additions for two points associated with background scattering. It is assumed that this mixture was used to establish the background scattering component of the measured intensities at the two values chosen for the analysis.

In highly crystalline samples, the uncertainty of analysis of each crystalline phase by the internal standard method leads to a large uncertainty in the content of the amorphous phase as determined by difference. In the certification of SRM 1878, Respirable Quartz, Hubbard 7 explored two methods to directly analyze for the amorphous content. The first consisted of a least squares fit of reference patterns to the observed pattern. This technique, just as the internal standard methods, requires a reference material that is 100 percent crystalline, a goal that 


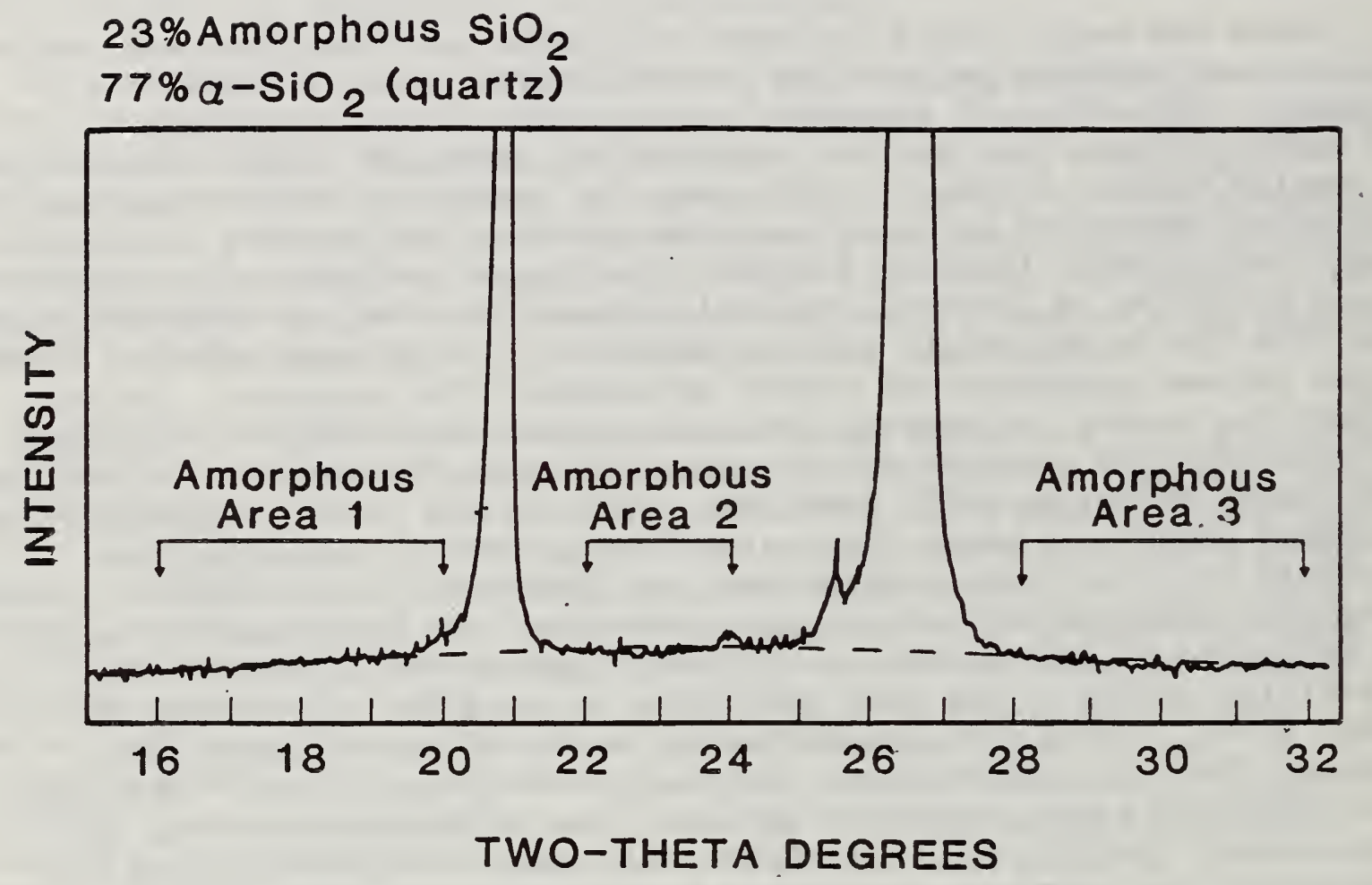

Figure 1. Amorphous Regions and Reference Lines used in Glass Phase Quantitative Analysis of Quartz. 
is effectively impossible. to achieve. The second method, which was adopted for the certification, was a modified method of additions. In this approach, the required reference material is a 100 percent amorphous phase, a requirement easily met in practice. Three amorphous areas and two Bragg diffraction reference lines were chosen for the quartz analysis as shown in Figure 1. The contribution to the observed intensity by low concentrations of the amorphous phase, will be low and corrections for background scattering will be important. Background scattering arises from several sources: scattering from slits, scattering from the air, and incoherent scattering from the sample. Incoherent scattering is a function of atomic number and scattering angle. Thus, to obtain an approximation to the total background, a material of similar elemental composition is required. Single crystal quartz ground to approximately 10 microns was used to establish the background intensity for the amorphous regions.

Recently, Nakamura et al. ${ }^{8}$, studied the method of additions for direct determination of amorphous content in quartz. For high initial concentrations of amorphous material the halo can be identified and matched by carefully choosing an amorphous analyte material. Nakamura found the results obtained with an external standard analysis compared well with those obtained with the additions method. In cases of low concentration of amorphous phase the matching of amorphous analyte is not possible as the halo intensity is quite low.

The need for a rapid, direct measurement of amorphous content in ceramic materials led to the evaluation of the present crystalline quantitative techniques. The standard additions method was subsequently modified for direct amorphous determination.

\section{THEORY OF METHOD OF ADDITIONS}

The intensity of diffraction line $i$ of phase a from a flat brickette is given by the equation ${ }^{9}$

$$
I_{i \alpha}=K_{i \alpha} \quad X_{\alpha} /\left[\begin{array}{ll}
\rho_{\alpha} & (\mu / \rho)_{m}
\end{array}\right]
$$

where $X_{\alpha}$ is the weight fraction of phase $\alpha, \rho_{\alpha}$ is the density of phase $\alpha$, $(\mu / \rho)_{m}$ is the mass absorption coefficient of the mixture and $K_{i \alpha}$ is a constant determined by the crystal structure, diffraction line and set of experimental conditions. Let $\beta$ represent a second phase in the same sample, the ratio of intensities of the two phases is given by

$$
\frac{I_{i \alpha}}{I_{j \beta}}=\frac{K_{i \alpha} \rho_{\beta} X_{\alpha}}{K_{j \beta} \rho_{\alpha} X_{\beta}}
$$

By definition $X_{\alpha}$ is the original number of grams of phase $\alpha$ per gram . of sample, and $X_{\beta}$ is the grams of phase $\beta$ per gram of sample. If we add $Y_{\alpha}$ grams of phase $\alpha$ per gram of sample, then the new concentration $X_{\alpha}^{\prime}$ and $X^{\prime}{ }_{\beta}$ are given by

$$
X_{\alpha}^{\prime}=\left(X_{\alpha}+Y_{\alpha}\right) /\left(1+Y_{\alpha}\right) \text { and }
$$




$$
\mathrm{X}^{\prime}{ }_{\beta}=\mathrm{X}_{\beta} /\left(1+\mathrm{Y}_{\alpha}\right) .
$$

Since the ratio of the intensity of line $i$ from phase $\alpha$ to line $j$ of phase $\beta$ is given by equation (2) then after adding $\mathrm{Y}_{\alpha}$ grams of phase $\alpha$ per gram of original sample the ratio of intensities is given by

$$
\frac{I^{\prime}{ }_{1 \alpha}}{I^{\prime}{ }_{j \beta}}=\frac{K_{1 \alpha} \rho_{\beta} X^{\prime}{ }_{\alpha}}{K_{j \beta} \rho_{\alpha} X^{\prime}{ }_{\beta}}=\frac{K_{1 \alpha} \rho_{\beta}\left(X_{\alpha}+Y_{\alpha}\right)}{K_{j \beta} \rho_{\alpha} X_{\beta}}
$$

which can be simplified to

$$
I^{\prime}{ }_{1 \alpha} / I^{\prime}{ }_{j \beta}=K\left(X_{\alpha}+Y_{\alpha}\right)
$$

where $K$ is the slope of a plot of $I^{\prime}{ }_{1 \alpha} / I^{\prime}{ }_{j \beta}$ versus $Y_{\alpha}$ with $Y_{\alpha}$ in units of grams of analyte added per gram of sample. Extrapolation to the negative $x$-intercept gives $X_{\alpha}$, which is the original amount of phase $\alpha$ in the sample. Multiple measures of the initial weight fraction $\mathrm{X}_{\alpha}$ are possible through inclusion of several independent measures of intensity $(i=1,2,3 \ldots)$ and $(j=1,2,3 \ldots)$.

\section{EXPERIMENTAL CONSIDERATIONS}

Acceptance testing of the respirable cristobalite powder required $x$-ray powder diffraction analyses to assure the qualitative purity of the the powder. Certification required: proof of homogeneity and measurement of crystallinity. Quantitative phase analyses were used to prove that there was little bottle-to-bottle variation. Once the material was bottled, the 500 bottles were randomly sampled and tested to ensure homogeneity.

One excellent indicator of possible sample inhomogeneity is measurement and comparison of lattice parameters. X-ray measurement of cell constants are often sensitive to variations of several parts in one hundred thousand. If these variations in lattice parameters were observed, they would indicate variations in chemical composition within the host crystal lattice. A less sensitive $x$-ray technique is the measurement of relative intensities, which is only accurate to a few percent changes in chemical composition of the crystal lattice. Another check on homogeneity is particle size analysis. Relative intensities were also compared to calculated values to check for an overall variation in the material and the possibility of preferred orientation.

To test for phase homogeneity and to certify the crystallinity of the sample two methods of quantitative $x$-ray analysis were performed. Measurement of the reference intensity ratio (RIR) of the cristobalite relative to $\mathrm{Cr}_{2} \mathrm{O}_{3}$ (SRM 674) provides a measure of relative crystallinity with a sensitivity of approximately 5 weight percent. Comparison to the calculated RIR should give an overall indication of crystallinity. The theory of the reference intensity ratio has been well documented in the literature $2,10,11$. The modified method of additions gave a direct measure of the amorphous content of the cristobalite. As a check on both methods, a hot phosphoric acid wash of the cristobalite specimen was used to 
prefefentially remove amorphous material from the surface. Both quantitative analyses were performed again to check the validity and sensitivity of the techniques.

In order to implement the method of additions, three data collection regions were identified as areas of the amorphous halo not interfering with Bragg diffraction peaks of cristobalite. Area 1 lies in the two-theta interval from 16.0 to 19.5 degrees, area 2 lies between 23.5 and 24.5 degrees two-theta and area 3 is in the two-theta region from 26.0 to 27.5 degrees, ( $\left.\lambda_{\mathrm{cuk}_{\alpha}}\right)$. Three reference lines of cristobalite, the (101) and (102) reflections and the $(200,112)$ doublet were selected for the analysis. The integration range for these reflections were 20.0 to 23.4 degrees twotheta, 30.6 to 32.3 degrees two-theta and 35.1 through 37.2 degrees twotheta, respectively. The reflections were chosen such that their intensities were high enough to minimize counting errors and they were close in position to the amorphous areas of interest. These selections enable multiple measurements ( 9 per sample) of the amorphous content ( 3 areas $\times 3$ reference lines). The total counting time for integrating each reference line and area was minimized utilizing a fixed error mode. The counting error specified was 18 with a maximum counting time of 10 minutes. If the total counting time to achieve a 18 counting error exceeds the preset $\mathrm{T}_{\mathrm{MAX}}$ of 10 minutes, then the minimum error achievable within $\mathrm{T}_{\mathrm{MAx}}$ is obtained to avoid excessively long count times integrating weak peaks. All peaks/areas had counting errors less than $0.05 \%$ and maximum counting times never exceeded $\mathrm{T}_{\text {MAX }}$.

In theory the method of additions requires measurement of the ratio $I_{i \alpha} / I_{j \beta}$, equation (6). $I_{i \alpha}$ is the measured intensity of the amorphous phase corrected for background and $I_{j \beta}$ is the background corrected intensity of a reference line from the crystalline cristobalite. Hence, the first step in applying the method of additions for this analysis requires estimation of the instrumental background using a highly crystalline material with the same chemical composition as the analyte and with a particle size less than 10 microns. Quartz powder ground from a single crystal and passed through a 400 mesh screen, was used to estimate the background. Next, a material close in composition to the amorphous phase present was chosen. Generally the position of the amorphous halo of the analyte to the diluent should be matched. In this case the position and shape of the amorphous halo of the amorphous material present in the cristobalite could not be determined. A fused quartz was chosen as a representative material. The technique involves measurement of the original material and comparison of that to various "spiked" samples. The ratio of the amorphous intensity to the reference line intensity above background was calculated for several reference lines and amorphous areas for all test samples. Linear regression analysis was performed on the data and extrapolated to the negative $x$-intercept. This value is the weight percent amorphous phase present in the starting material: 


\section{MATERIALS AND EXPERIMENTAL PROCEDURE}

Cristobalite was prepared for NBS by the Trans Tech Company using Berkeley 5 micron MIN-U-SIL(R)* A two kilogram sample was heated at $1600^{\circ} \mathrm{C}$ for eight hours. The sample was then air quenched, treated with $6 \mathrm{~N}$ $\mathrm{HCl}$ and jet-milled. The +325 mesh fraction was then removed by sieving.

Chemical analysis of the as-received cristobalite was performed by d.c. arc emission spectroscopy with samples compared to a commercially prepared $\mathrm{SiO}_{2}$-based reference material. Preliminary $\mathrm{x}$-ray diffraction analysis was carried out using a vertical $x$-ray diffractometer equipped with a diffracted beam graphite crystal monochromator, Cu Ka radiation from a $\mathrm{Cu}$ long fine-focus tube operated at $40 \mathrm{kv}$ and $35 \mathrm{ma}$. A powder pattern was collected at $1 / 8^{\circ} 2 \theta$ per minute from $5^{\circ}$ to $90^{\circ} 2 \theta$. Further qualitative analysis was conducted on a Guinier - de Wolff camera.

The material was mixed thoroughly and bottled in 5 gram amounts. A total of 500 bottles were prepared. Sixteen bottles were randomly selected for material homogeneity and crystalline content testing.

Subsequent $\mathrm{x}$-ray measurements for qualitative and quantitative analysis were carried out on vertical goniometers with $\mathrm{Cu}$ long fine-focus $x$-ray tubes operated at $40 \mathrm{kv}$ and $35 \mathrm{ma}$, equipped with diffracted beam, graphite crystal monochromators and scintillation counters. The diffraction unit designated AM-1 utilizes a flat specimen geometry and samples were mounted according to the d-spacing and intensity sample mounting methods described by McMurdie ${ }^{12}$ et al. Measurements made on AM-1 were performed with a 0.1 degree receiving slit. The unit designated AM-2 was equipped with a sample spinner, and measurements were made with a 0.2 degree receiving slit. Intensity data were collected on both units. All data collection was automated using NBS*AUTO ${ }^{13}$.

The particle size distribution was determined using a commercially available $\mathrm{x}$-ray sedigraph and particle dispersion liquids. Analyses were made at $34^{\circ} \mathrm{C}$ with a liquid of density $0.748 \mathrm{~g} / \mathrm{cc}$ and a viscosity of 1.34 centipoise. A 90 to 1.38 micron range was scanned for each sample. Nine samples were randomly selected for analysis and these were analyzed in duplicate or triplicate. Samples were dispersed ultrasonically for three minutes and magnetically stirred for five minutes prior to analysis.

The density of the cristobalite powder was determined with a helium autopycnometer. The sample was placed in a sealable container and dried at $100^{\circ} \mathrm{C}$ in a vacuum oven for three hours. The container with sample was then removed from the oven and placed in a desiccator. The sample was allowed to cool to room temperature and sealed before weighing. Six determinations of density were made on one sample of cristobalite.

For accurate lattice parameter measurement the cristobalite was mixed with tungsten for high angle calibration and fluorophlogopite (SRM 675) for

Commercial equipment or materials are identified in this paper to adequately describe the experimental procedure and do not imply endorsement by the National Bureau of Standards. 
low angle calibration. The choice of internal standard depends upon the need for low and/or high angle calibration and unobstructed reflections. Mixtures were prepared such that the intensities of the strongest reflection from each phase were within a factor of two. Approximately one gram mixtures were thoroughly combined using a small porcelain mortar and pestle. Samples from 16 bottles were analyzed. Digital data was collected from $5^{\circ}$ to $90^{\circ} 2 \theta$, with a $0.01^{\circ} 2 \theta$ step width for either 7 or 15 hours. All data was processed with the series of programs JCPDS-NBS Powder Pattern ${ }^{14}$ and lattice constants were refined by JCPDS-NBS*LSQ85 derived from the program of Appleman and Evans ${ }^{15}$.

Relative intensities were also measured for each test sample. To reduce the possibility of preferred orientation each sample was mixed with approximately equal portions of amorphous fused quartz. A side-drifted mount was also used to further promote randomization of particles. As a check on instrumental variation, samples were also run on AM-2 using a sample spinner, which improves particle statistics. The intensities of all reflections between $15^{\circ}$ and $50^{\circ} 2 \theta$ were collected and relative integrated intensities were determined by NBS*QUANT $84^{1} 0$. For comparison, relative intensities were calculated using POWD12 16 and space group, lattice constants, atomic positions and thermal parameters of cristobalite ${ }^{17,18}$.

To check for preferred orientation, samples from bottles 211 and 282 were packed into a front loading sample holder. Preferred orientation was induced by pressing on the front surface with a smooth microscope slide. A sample from bottle 282 was also prepared in a manner analogous to that used by clay scientists ${ }^{19}$ to orient plate-like clay particles. The sample was mixed with water, dropped on a glass slide, and dried overnight. This method causes plate-like particles such as clays to orient face up thus inducing preferred orientation of the sample. Relative intensities were measured from these samples. Optical and scanning electron microscopy were utilized to check particle shape.

Two quantitative $\mathrm{x}$-ray analyses were performed: intensity ratio (RIR) of cristobalite was measured as crystallinity; and, (2) a direct determination of the amorphous content of the cristobalite using a modified method of additions. RIR's were measured from mixtures of 30 percent cristobalite by weight with 70 percent chromium oxide by weight. The (101), (111), (102), (113), and (212) reflections of cristobalite and the (104) and (006) reflections of $\mathrm{Cr}_{2} \mathrm{O}_{3}$ were chosen for this analysis because they were free from interference with other diffraction peaks. Samples were mixed and blended with a small mortar and pestle. Both diffraction units were employed as a check on instrumental variation, utilizing the appropriate mounting methods. The RIR's of all sixteen samples of cristobalite were obtained from data processed by program RUNFIL of NBS *QUANT84.

The direct determination of the amorphous silica content in cristobalite by the modified method of additions requires measurement of the undiluted samples and at least one diluted or spiked sample. For the purposes of certification three or more spiked samples were prepared to permit error analysis. Only AM-2 was chosen for this analysis as it was optimized for intensity measurements. The spiking material chosen was fused quartz and three spiked mixtures $(6,11$, and 24 percent by weight 
fused quartz) were prepared for samples from eight bottles of cristobalite. A fourth spiked mixture containing 30 percent by weight fused quartz was prepared for two samples of cristobalite. Spiked mixtures substituting silica gel for the fused quartz were prepared for one sample.

Approximately one gram mixtures of cristobalite with diluent were combined in a small porcelain mortar and pestle and mounted in the holder of the sample spinner and intensities were measured according to the preceding conditions for AM-2. All x-ray data was processed with program AMORPH of NBS*QUANT 84 .

As a check on this method, a sample of cristobalite was also acid washed with hot orthophosphoric acid in an attempt to enhance the dissolution of amorphous relative to crystalline cristobalite. The procedure outlined by Stephen Altree-Williams ${ }^{20}$ et al. was followed. The sample was collected by vacuum filtration with a nuclepore $0.22 \mu \mathrm{m}$ filter and rinsed several times with distilled water. The residue was dried at $105^{\circ} \mathrm{C}$ for approximately 5 hours, cooled in a desiccator and measured following the conditions outlined above.

\section{RESULTS}

The results of the preliminary chemical analysis of the lot of cristobalite appear in Table 1. The cristobalite was compared to a commercially prepared $\mathrm{SiO}_{2}$ reference material and impurity concentrations are reported in parts per million (ppm). The results of the Guinier - de Wolff analysis of the cristobalite powder showed no phase impurities. The slowly collected powder diffraction pattern of the cristobalite is shown in Figure 2 .

The results of the $x$-ray sedigraph analysis of the particle size distribution of the samples of cristobalite are found in Table 2 . On average 97 percent by mass of the cristobalite particles were finer than 10 $\mu \mathrm{m}, 50$ percent by mass of the particles were finer than $3.3 \mu \mathrm{m}$, and eight percent by mass were finer than $2 \mu \mathrm{m}$. The particle size distributions of each sample of cristobalite show little variability from sample to sample. Any small variability is within the error of measurement given the tendency of the cristobalite to agglomerate. The results of the helium autopycnometer density measurement gave an experimental density of 2.344 $\mathrm{g} / \mathrm{cc} \pm 0.004 \mathrm{~g} / \mathrm{cc}$ as compared to the calculated density of $2.317 \mathrm{~g} / \mathrm{cc}$.

Sixteen randomly sampled bottles of cristobalite were first tested for homogeneity of crystalline cristobalite. Digital data were processed with the analysis package JCPDS-NBS POWDER PATTERN, a series of programs which reads the digital data and determines peak positions by the second derivative technique as described by McMurdie ${ }^{12}$ et al. Sample peaks which are partially or completely hidden by standard peaks were read from strip chart recordings of the sample diffraction pattern (Figure 2), then PLOT.PATTERN was used to plot the powder pattern on a scale of one degree per inch and each pattern was visually inspected (Figure 3). A polynomial correction curve was then calculated by the program POWDER.CALIBR. An instrument $2 \theta$ calibration correction was applied to both sample and internal standard $2 \theta$ positions. Next, an internal standard calibration curve was derived from the observed and instrument corrected internal standard peak positions and their theoretical positions. The resulting 
Table 1. Chemical Analysis of As-Received Cristobalite by D.C. Arc Emission Spectroscopy

\section{SAKIPIE}

\section{ELEMIENT}

Ag

Al

B

$\mathrm{Ba}$

$\mathrm{Be}$

Bi

$\mathrm{Ca}$

$\mathrm{Cr}$

$\mathrm{Cu}$

$\mathrm{Fe}$

K

Li

$\mathrm{Mg}$

Mn

Mo

$\mathrm{Na}$

$\mathrm{Ni}$

$\mathrm{Pb}$

$\mathrm{Rb}$

Si

$\mathrm{Sn}$

$\mathrm{Sr}$

Ti

$\mathrm{V}$

$\mathrm{Zn}$

$\mathrm{Zr}$

\section{1}

$<10$ ppm

1000

$<100$

10

$<10$

$<10$

200

10

3
500

$<100$

$<10$

100

$<10$

$<10$

200

10

$<100$

$<100$

$\mathrm{XXXX}$

$<50$

$<50$

100

$<10$

$<100$

40

\section{2}

$$
\begin{array}{r}
<10 \text { ppm } \\
1000 \\
<100 \\
10 \\
<10 \\
<10
\end{array}
$$

200

10

5

500

$<100$

$<10$

100

$<10$

$<10$

200

10

$<100$

$<100$

XXXX

$<50$

$<50$

100

$<10$

$<100$ 

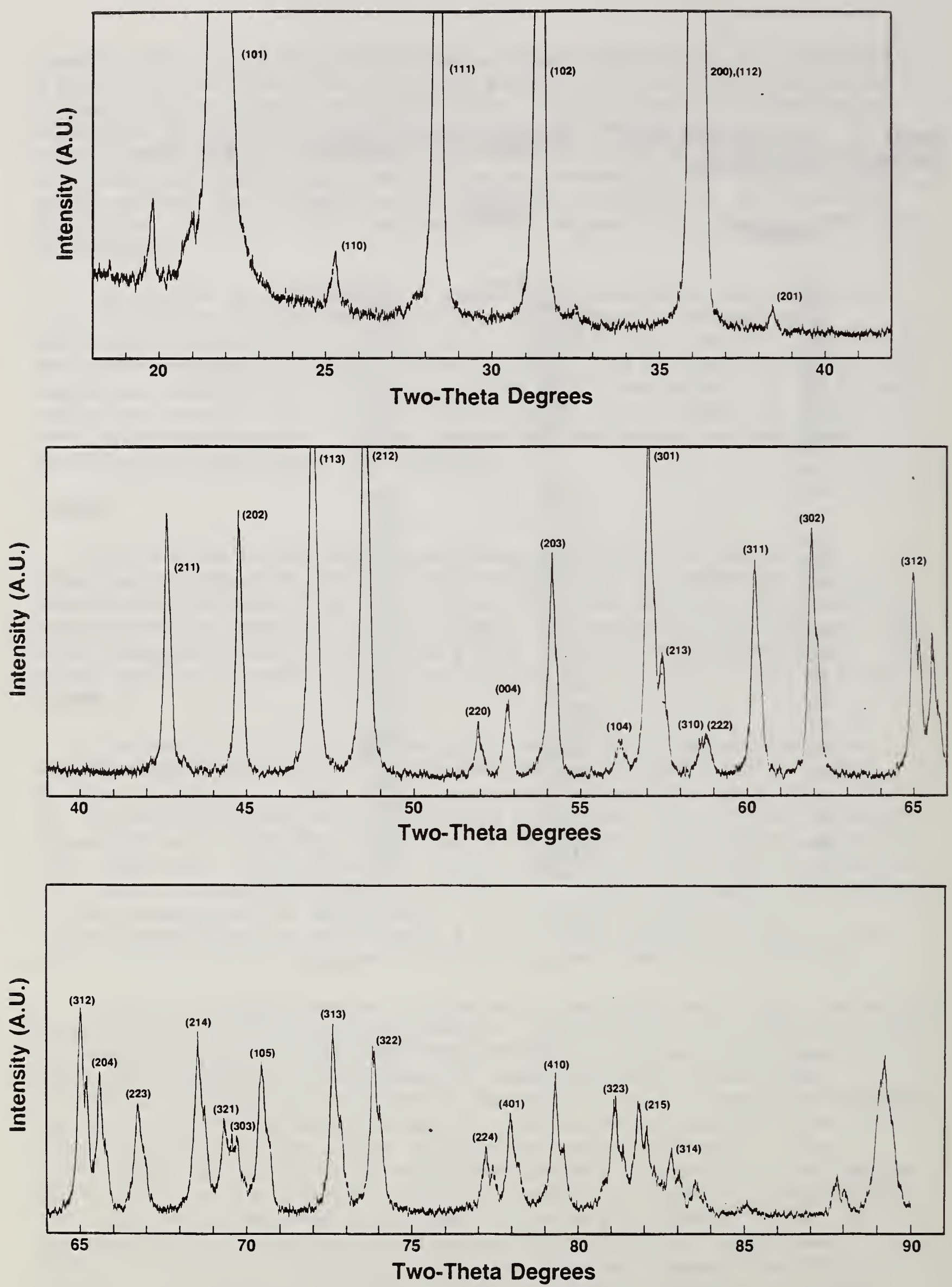

Figure 2. X-Ray Diffraction Pattern of Cristobalite from 0 to 90 Degrees Two-Theta. $\quad 16$ 
Table 2. Equivalent Spherical Diameters of Cristobalite Measured Using An $\mathrm{X}$-Ray Sedigraph Technique

\begin{tabular}{|c|c|c|c|c|c|c|c|c|c|c|c|}
\hline \multirow{3}{*}{\multicolumn{2}{|c|}{$\begin{array}{l}\text { BOTTLE } \\
\text { NUMBER }\end{array}$}} & \multicolumn{9}{|c|}{ MASS \& FINER THAN } & \multirow{3}{*}{$\begin{array}{l}\text { 50\& BY MASS } \\
\text { FINER THAN } \\
\text { (Microns) }\end{array}$} \\
\hline & & \multicolumn{5}{|c|}{ EQUIVALENT SPHERICAL } & DIAME & \multicolumn{3}{|c|}{ (Microns) } & \\
\hline & & 10 & 9 & 8 & 7 & 6 & 5 & 4 & 3 & 2 & \\
\hline \multirow[t]{2}{*}{50} & A & 95 & 93 & 92 & 89 & 85 & 78 & 64 & 39 & 8 & 3.3 \\
\hline & B & 97 & 96 & 95 & 93 & 89 & 83 & 70 & 46 & 12 & 3.1 \\
\hline \multirow[t]{2}{*}{69} & A & 95 & 95 & 93 & 91 & 87 & 80 & 66 & 42 & 10 & 3.3 \\
\hline & B & 98 & 96 & 95 & 93 & 90 & 84 & 71 & 48 & 14 & 3.1 \\
\hline \multirow[t]{2}{*}{92} & A & 96 & 95 & 94 & 91 & 87 & 81 & 65 & 41 & 7 & 3.3 \\
\hline & B & 98 & 96 & 95 & 93 & 88 & 83 & 68 & 44 & 10 & 3.1 \\
\hline \multirow[t]{2}{*}{104} & A & 97 & 95 & 94 & 92 & 87 & 79 & 60 & 32 & 4 & 3.5 \\
\hline & B & 97 & 95 & 94 & 91 & 87 & 78 & 60 & 34 & 6 & 3.4 \\
\hline \multirow[t]{2}{*}{154} & A & 96 & 95 & 93 & 91 & 86 & 80 & 65 & 39 & 8 & 3.3 \\
\hline & B & 97 & 95 & 94 & 92 & 87 & 80 & 66 & 40 & 8 & 3.3 \\
\hline \multirow[t]{3}{*}{165} & A & 97 & 96 & 93 & 91 & 86 & 77 & 62 & 32 & 4 & 3.5 \\
\hline & B & 96 & 95 & 94 & 91 & 88 & 79 & 64 & 34 & 5 & 3.5 \\
\hline & C & 97 & 95 & 93 & 90 & 87 & 79 & 62 & 36 & 5 & 3.5 \\
\hline \multirow[t]{2}{*}{211} & A & 98 & 97 & 96 & 93 & 88 & 82 & 68 & 44 & 9 & 3.3 \\
\hline & B & 99 & 98 & 96 & 93 & 88 & 82 & 67 & 42 & 9 & 3.2 \\
\hline \multirow[t]{2}{*}{227} & A & 95 & 93 & 93 & 90 & 86 & 79 & 64 & 41 & 8 & 3.3 \\
\hline & B & 97 & 96 & 94 & 92 & 88 & 82 & 69 & 44 & 11 & 3.2 \\
\hline \multirow[t]{2}{*}{304} & A & 95 & 93 & 93 & 91 & 87 & 80 & 65 & 40 & 8 & 3.3 \\
\hline & B & 96 & 93 & 93 & 91 & 88 & 81 & 66 & 44 & 10 & 3.2 \\
\hline
\end{tabular}



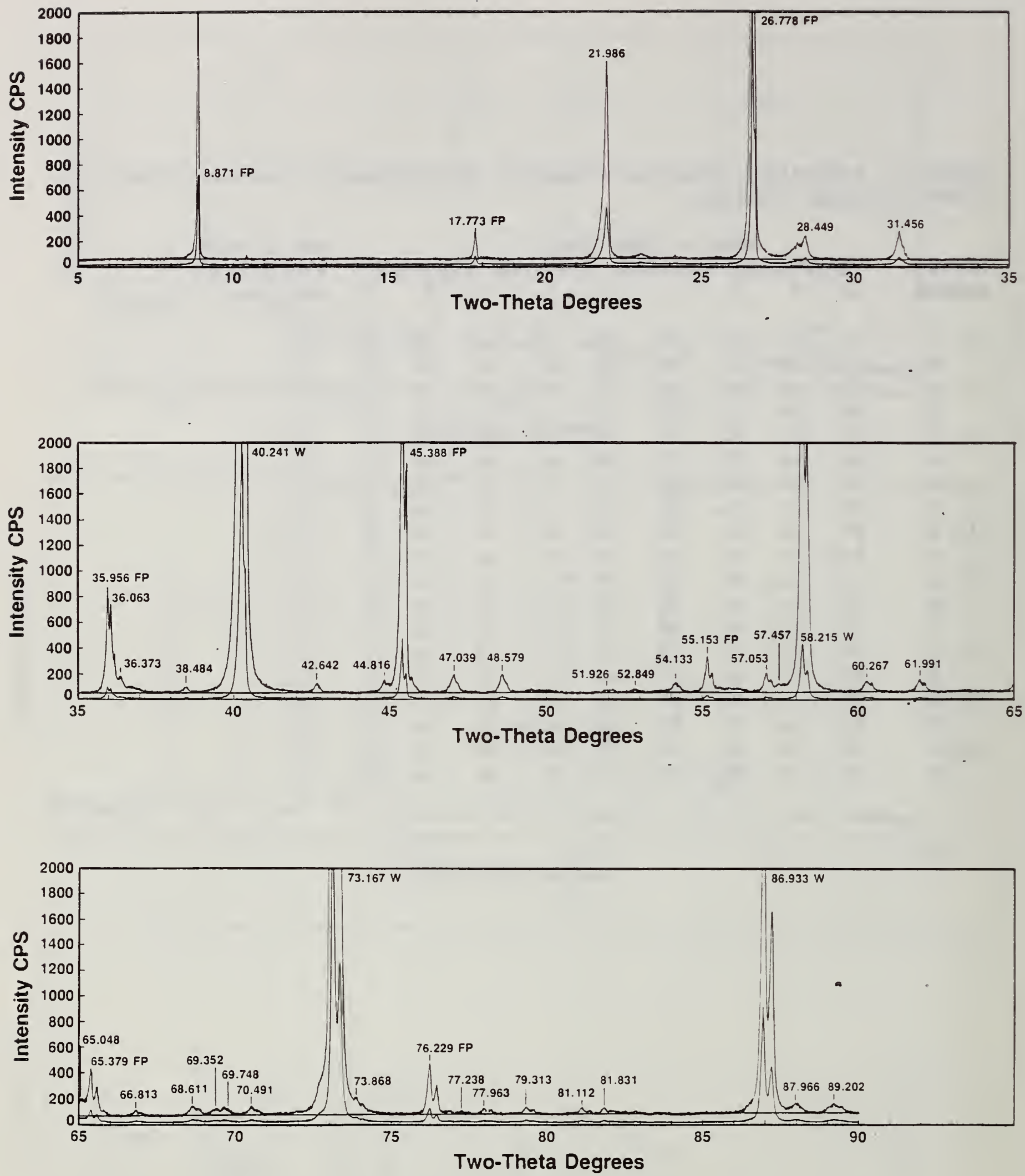

Key:

$W=$ Tungsten

$F P=$ Fluorophlogopite (SRM 675)

Figure 3. X-Ray Diffraction Pattern of Cristobalite Sample 10 Mixed with Tungsten for High Angle Calibration and Fluorophlogopite for Low Angle Calibration. 
polynomial correction was applied to all peaks of the pattern. The data reported in Table 3 was used by POWDER. CALIBR to generate the polynomial correction for a sample from bottle 211, corresponding to Table 6, Run 2 . An editing program, POWDER.EDTPKS was used to flag reflections for use in the least squares refinement. Generally, $\mathrm{Cu} \mathrm{K} \alpha_{2}$ reflections as well as partially overlapped sample reflections were excluded from the refinement. EDTPKS was also used to enter space group notation and preliminary lattice constants which were used for initial indexing and refinement. The least squares program JCPDS-NBS*LSQ82 was used to assign hkl's and refine lattice constants. The cell refinement was based upon corrected $2 \theta$ values and only those values which were unambiguously indexed. This program minimized the value $\sum\left(\theta_{C O R R}-\theta_{C A L C}\right)^{2}$. The information reported in Table 4 was used for the least squares refinement of data for the lattice parameter determination corresponding to sample 211 from Table 6; Run 2. The refined lattice parameters were measured for all 16 samples and results appear in Table 5. The average lattice parameters and standard deviations were $\langle A\rangle=4.9732(7)$ and $\langle C\rangle=6.9226(10)$.

To examine the precision of the lattice parameter measurements one bottle was chosen to be repeatedly tested. Test 1 consisted of mounting the sample and collecting three $x$-ray diffraction patterns, the only variation being that the sample holder was removed from the diffractometer after each measurement and reinserted for each new measurement. For test 2 the sample was mounted and inserted in the diffractometer, AM-1. Data for three consecutive runs was collected without disturbing it in any way between measurements. Test 3 involved remounting the sample for each of three measurements. Test 4 required that two new mixtures be prepared from the test bottle and that three completely different samples were measured. The results of these tests are shown in Tables 6-9.

The relative intensities of samples from all 16 bottles were measured. All reflections less than $50^{\circ} 2 \theta$ were collected. AUTO requested all information required for the specified analysis at the time of data collection. In order to measure the relative intensities the peak regions were defined. From a strip chart recording a low angle background value and a high angle background value were selected such that the tails of the peak were not contributing intensity at these two values. AUTO also requested an approximate peak position, generally the top of the peak as read off the strip chart recording. For the fixed error mode, AUTO requested the desired or tolerable error in the final net intensity (18) and the maximum counting time (10 minutes). The digital data was converted into a counts per second scale, and the net background corrected intensity was computed ${ }^{10}$. The relative intensities were computed from the equation

$$
I^{R E I, \alpha}=I_{i, \alpha} / I_{x, \alpha}
$$

where $I_{i, \alpha}$ is the intensity of line $i$ and $I_{x, \alpha}$ is the intensity of the strongest line for phase $\alpha$. The digital data from the relative intensity measurements were plotted area by area to visually inspect any changes in profile shape or background that could cause changes in measured intensities and to ensure that the correct areas were being measured. No changes were observed. The results appear in Table 10. 
Table 3. Internal Standard Peak Positions used to Determine the Polynomial Correction for the Cristobalite Reflections Corresponding to Sample 211 from Table 6 , Run 2

\begin{tabular}{|c|c|c|c|c|c|}
\hline $\begin{array}{l}\text { STANDARD } \\
\text { TYPE }\end{array}$ & $2 \theta^{R}=\pi$ & $2 \theta^{\operatorname{Cox} x}$ & $2 \theta^{\operatorname{Th} \theta x}$ & $2 \theta^{c} \cdot 1 c$ & $\begin{array}{c}\text { ERROR } \\
2 \theta\end{array}$ \\
\hline FP & 8.871 & 8.834 & 8.853 & 8.851 & .002 \\
\hline FP & 17.773 & 17.753 & 17.759 & 17.762 & -.003 \\
\hline FP & 26.778 & 26.772 & 26.774 & 26.776 & -.002 \\
\hline$W$ & 40.241 & 40.252 & 40.262 & 40.256 & .006 \\
\hline $\mathrm{W}$ & 58.215 & 58.243 & 58.251 & 58.254 & -.003 \\
\hline$W$ & 86.993 & 86.985 & 86.996 & 86.996 & .000 \\
\hline
\end{tabular}


Table 4. Observed, Corrected and Calculated $2 \theta$ and D-spacing Values from Least Squares Refinement of Data for Lattice Parameter Determination Corresponding to Sample 211 from Table 6, Run 2.

\begin{tabular}{|c|c|c|c|c|}
\hline HKLL & $2 \theta_{\mathrm{obs}}$ & $2 \theta_{\text {Corr }}$ & $2 \theta_{\mathrm{Calc}}$ & $\begin{array}{l}\mathrm{D}_{\text {Obs }}^{\mathrm{Coxx}} \\
\end{array}$ \\
\hline 101 & $21.986^{\circ}$ & $21.979^{\circ}$ & $21.989^{\circ}$ & $4.0408 \AA$ \\
\hline 110 & 25.343 & 25.340 & 25.305 & 3.5120 \\
\hline 111 & 28.449 & 28.449 & 28.444 & 3.1348 \\
\hline 102 & 31.456 & 31.460 & 31.460 & 2.8413 \\
\hline 200 & 36.063 & 36.073 & 36.073 & 2.4879 \\
\hline 112 & 36.373 & 36.383 & 36.391 & 2.4674 \\
\hline 201 & 38.484 & 38.497 & 38.434 & 2.3366 \\
\hline 211 & 42.642 & 42.661 & 42.663 & 2.1177 \\
\hline 202 & 44.816 & 44.837 & 44.844 & 2.0198 \\
\hline 113 & 47.039 & 47.063 & 47.066 & 1.9293 \\
\hline 212 & 48.579 & 48.605 & 48.620 & 1.8717 \\
\hline 220 & 51.926 & 51.957 & 51.962 & 1.7585 \\
\hline 004 & 52.849 & 52.881 & 52.861 & 1.7300 \\
\hline 203 & 54.133 & 54.167 & 54.183 & 1.6919 \\
\hline 104 & 56.214 & 56.250 & 56.236 & 1.6341 \\
\hline 301 & 57.053 & 57.090 & 57.082 & 1.6120 \\
\hline 213 & 57.457 & 57.495 & 57.505 & 1.6016 \\
\hline 310 & 58.611 & 58.650 & 58.652 & 1.5728 \\
\hline 222 & 58.830 & 58.870 & 58.860 & 1.5674 \\
\hline 311 & 60.267 & 60.308 & 60.299 & 1.5335 \\
\hline 302 & 61.991 & 62.034 & 62.021 & 1.4949 \\
\hline 312 & 65.048 & 65.095 & 65.091 & 1.4318 \\
\hline 204 & 65.633 & 65.680 & 65.679 & 1.4204 \\
\hline 223 & 66.813 & 66.862 & 66.840 & 1.3982 \\
\hline 214 & 68.611 & 68.662 & 68.662 & 1.3658 \\
\hline 321 & 69.352 & 69.403 & 69.419 & 1.3531 \\
\hline 303 & 69.748 & 69.800 & 69.799 & 1.3463 \\
\hline 105 & 70.491 & 70.543 & 70.556 & 1.3340 \\
\hline 313 & 72.636 & 72.690 & 72.702 & 1.2998 \\
\hline 322 & 73.868 & 73.923 & 73.904 & 1.2811 \\
\hline 224 & 77.238 & 77.296 & 77.295 & 1.2334 \\
\hline 401 & 77.963 & 78.021 & 78.018 & 1.2237 \\
\hline 410 & 79.313 & 79.372 & 79.374 & 1.2063 \\
\hline 323 & 81.112 & 81.172 & 81.175 & 1.1840 \\
\hline 215 & 81.831 & 81.892 & 81.896 & 1.1754 \\
\hline 314 & 82.779 & 82.840 & 82.878 & 1.1643 \\
\hline
\end{tabular}

* $2 \theta_{\mathrm{Calc}}$ is based upon the refined cell. 
Table 5. Lattice Parameters Measured from 16 Randomly Selected Bottles, Procedure as outlined in Powder Diffraction with $W$ and FP as two theta calibration standards.

\begin{tabular}{lcccc} 
BOTTLE & \multicolumn{4}{c}{ LATTICE PARAMETERS } \\
NUMBER & $\mathbf{a}$ & $\boldsymbol{\sigma}$ & $\boldsymbol{c}$ & $\boldsymbol{\sigma}$ \\
& & & & \\
10 & 4.973014 & .000212 & 6.922584 & .000481 \\
23 & 4.971610 & .000302 & 6.921444 & .000736 \\
50 & 4.974654 & .000241 & 6.920568 & .000635 \\
69 & 4.973358 & .000205 & 6.922301 & .000441 \\
92 & 4.973999 & .000209 & 6.922479 & .000469 \\
104 & 4.973862 & .000283 & 6.923643 & .000714 \\
126 & 4.973345 & .000247 & 6.923554 & .000530 \\
154 & 4.972303 & .000278 & 6.921087 & .000648 \\
165 & 4.972804 & .000256 & 6.922750 & .000566 \\
187 & 4.972641 & .000263 & 6.922160 & .000640 \\
211 & 4.973455 & .000362 & 6.923040 & .000687 \\
227 & 4.973526 & .000255 & 6.923748 & .000544 \\
253 & 4.972392 & .000265 & 6.924079 & .000658 \\
274 & 4.973977 & .000243 & 6.922927 & .000535 \\
282 & 4.973427 & .000191 & 6.922072 & .000416 \\
304 & 4.973213 & .000227 & 6.923531 & .000532 \\
& & & & \\
ALL* * & 4.97322 & & 6.92262 & \\
SD $^{* *}$ * & 0.00073 & & &
\end{tabular}

* Tetragonal symmetry, with Space Group $\mathrm{P}_{1} 2_{1} 2$; a and $c$ are lattice parameters in $\dot{A}$. $\sigma$ is the estimated standard deviation from least-squares cell refinement of 36 calibrated reflections.

* $\quad$ ALL $=1 / n \cdot \sum_{i=1}^{n} \dot{a}_{i}$

*** SD $\underset{i=1}{n}\left\{\sum\left(a_{i}-\langle a\rangle\right)^{2} /(n-1)\right\}^{1 / 2}$ 
Table 6. Lattice Parameters Test A (B\#211) - Sample Mounted Once, Removed $\&$ Reinserted for Three Runs in Diffractometer

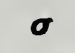

c

$\sigma$

$\begin{array}{lllll}\text { Run 1 } & 4.973575 & .000223 & 6.922071 & .000457 \\ \text { Run 2 } & 4.973466 & .000211 & 6.922291 & .000461 \\ \text { Run 3 } & 4.973709 & .000220 & 6.923043 & .000485\end{array}$
ALL
4.97358
6.92247
SD
0.00010
0.00042

Table 7. Lattice Parameters Test B (B\#211) - Sample Mounted Once, Three Consecutive X-Ray Runs Without Removing Sample

a

$$
\begin{array}{ll}
4.974218 & .000277 \\
4.973122 & .000257
\end{array}
$$

Run 2

Run 3 c

$\begin{array}{ll}6.923722 & .000589 \\ 6.924218 & .000517 \\ 6.922786 & .000546\end{array}$
ALL
4.97349
6.92358
SD
0.00051
0.00059

Table 8. Lattice Parameters Test C (B\#211) - Sample Remounted Between Each of Three X-Ray Analyses

a

Run 1

Run 2

Run 3

ALI

$\mathrm{SD}$

$$
\begin{array}{ll}
4.973657 & .000210 \\
4.973597 & .000226 \\
4.973159 & .000314
\end{array}
$$

4.97347

0.00022 c
6.923682
.000442
6.922207
.000489
6.923353
.000593

6.92308

0.00063

Table 9. Lattice-Parameters Test D (B\#211) - Three Mixtures, Same Bottle, One X-Ray Analysis Each

a

$\sigma$

c

$\sigma$

Run 1

$$
\begin{array}{ll}
4.973446 & .000224 \\
4.972922 & .000294 \\
4.973657 & .000210
\end{array}
$$

$6.922810 \quad .000480$

Run 2

$6.923252 \quad .000595$

Run 3

6.923682

.000442
ALL
4.97334
6.92325
SD
0.00031
0.00036 
Table 10. Relative Intensity Data - Cristobalite

BOTTLE

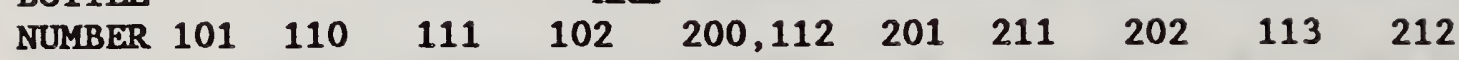

AM-2

$\begin{array}{rlllllllllll}10 & 100 & .636 & 8.837 & 10.714 & 17.176 & .198 & 2.714 & 2.464 & 4.989 & 4.941 \\ 10 & 100 & .543 & 8.564 & 10.547 & 17.249 & .175 & 2.756 & 2.503 & 4.983 & 4.968 \\ 23 & 100 & .539 & 8.598 & 10.722 & 17.225 & .152 & 2.748 & 2.475 & 5.008 & 4.961 \\ 50 & 100 & .507 & 8.572 & 10.445 & 17.066 & .135 & 2.680 & 2.504 & 4.892 & 4.872 \\ 69 & 100 & .493 & 8.750 & 10.926 & 17.636 & .165 & 2.785 & 2.526 & 5.046 & 5.020 \\ 92 & 100 & .489 & 8.605 & 10.699 & 17.227 & .222 & 2.731 & 2.485 & 5.036 & 4.957 \\ 104 & 100 & .538 & 8.715 & 10.768 & 17.290 & .134 & 2.700 & 2.528 & 5.019 & 5.060 \\ 126 & 100 & .411 & 8.634 & 10.796 & 17.686 & .184 & 2.814 & 2.485 & 5.107 & 5.043 \\ 154 & 100 & .491 & 8.513 & 10.563 & 17.259 & .185 & 2.669 & 2.480 & 4.931 & 4.877 \\ 165 & 100 & .527 & 8.576 & 10.814 & 17.439 & .173 & 2.751 & 2.514 & 4.977 & 5.017 \\ 187 & 100 & .620 & 8.916 & 10.940 & 17.840 & .190 & 2.814 & 2.560 & 5.174 & 5.119 \\ 211 & 100 & .572 & 8.654 & 10.764 & 17.325 & .136 & 2.707 & 2.492 & 5.003 & 4.974\end{array}$

ALI

$\begin{array}{lrrrrrrrrrr}\text { AM-2 } & 100 & 0.50 & 8.7 & 10.7 & 17.4 & 0.20 & 2.7 & 2.50 & 5.0 & 5.0 \\ \text { SD } & -- & .06 & .1 & .1 & .2 & .03 & .1 & .03 & .1 & .1\end{array}$

AM-1

$\begin{array}{llllllllllllll}211 & 100 & .554 & 8.598 & 11.163 & 18.9 .09 & .119 & 2.975 & 2.665 & 5.324 & 5.664 \\ 227 & 100 & .536 & 8.679 & 10.746 & 17.401 & .171 & 2.745 & 2.505 & 5.021 & 4.992 \\ 253 & 100 & .558 & 8.895 & 10.758 & 17.721 & .205 & 3.059 & 2.611 & 5.001 & 5.218 \\ 274 & 100 & .473 & 8.809 & 10.743 & 17.611 & .291 & 3.085 & 2.602 & 5.124 & 5.394 \\ 282 & 100 & .565 & 8.670 & 10.780 & 17.772 & .267 & 2.873 & 2.658 & 4.990 & 5.384 \\ 304 & 100 & .491 & 8.484 & 10.798 & 17.896 & .186 & 2.954 & 2.493 & 4.955 & 5.217\end{array}$

ALI

$\begin{array}{lrrrrrrrrrr}\text { AM-1 } & 100 & 0.50 & 8.7 & 10.8 & 17.9 & 0.2 & 2.9 & 2.6 & 5.1 & 5.3 \\ \text { SD } & --- & .04 & .1 & .1 & .5 & .1 & .1 & .1 & .1 & .2\end{array}$

$\begin{array}{lrrrrrrrrrr}\text { ALL } & 100 & 0.50 & 8.7 & 10.8 & 17.5 & 0.20 & 2.8 & 2.5 & 5.0 & 5.1 \\ \text { SD } & -\ldots & .1 & .1 & .2 & .4 & .04 & .1 & .1 & .1 & .2\end{array}$

$\begin{array}{llllllllllll}\text { Calc } & & & & & & & & & \\ I^{\operatorname{Rel} 1} & 100^{\star} & 1 & 9 & 12 & 15,4 & 0 & 3 & 3 & 6 & 6 \\ I^{R e 1} & 100^{\star *} & 1 & 9 & 11 & 14,4 & 0 & 3 & 3 & 5 & 5\end{array}$

* Pattern calculated based upon $\mathrm{Si}^{+4}, \mathrm{O}^{-2}$ ions.

* Pattern calculated based upon neutral Si, 0 atoms. 
Two tests were performed to check the reproducibility of the measured relative intensities. In the first test, the relative intensities of the sample from bottle 10 were collected twice without disturbing the sample in any way between measurements. Variability in the relative intensities ranged from 2 percent for the (102) reflection to 3 percent for the (111) reflection, which lies within the expected reproducibility of this measurement. In the second test, the relative intensities of sample number 211 were measured on AM-1. Then the same sample was remounted and the relative intensities were measured using AM-2. The results indicated greater variability in the measured relative intensities, with a 10 percent variation in intensity for the $(200,112)$ doublet. The results of these two tests appear in Table 10.

The reference intensity ratio was measured for each sample. Chromium oxide was chosen as the reference material and mixed in a $70 / 30$ ratio by weight with cristobalite. As in the relative intensity measurement, AUTO requested all information for the specified analysis at the time of data collection, creating a runfile which specified the high and low background angles as well as the approximate peak position for all peaks of interest. Cristobalite peaks were labeled as the unknown, while $\mathrm{Cr}_{2} \mathrm{O}_{3}$ peaks were labeled as internal standard peaks. Each peak was counted utilizing the fixed error mode with one percent tolerable error in the final net intensity and 10 minutes maximum counting time. AUTO also requested the weight fraction of standard added to 1.0 grams of unknown. Then AUTO used this runfile to collect $x$-ray information for all samples for the analysis. Measurements were made initially on AM-1 and verified on AM-2. All intensity data was processed with Q85RNF from NBS*QUANT84. RIR's were calculated using the equation

$$
R_{\alpha, s}=\frac{I_{i \alpha} I_{j s} X_{s}}{I_{j s} I_{i \alpha} X_{\alpha}}
$$

where $I_{1 \alpha}$ is the intensity of line $i$ of phase $\alpha$ and $I_{j s}$ is the intensity of line $j$ of the standard phase, $I^{I \otimes l}$ is the relative intensity of the line of the respective phase, $X_{3}$ is the weight fraction of standard phase, $X_{\alpha}$ is the weight fraction of the sample phase and $R_{1} R_{\alpha, s}$ is the reference intensity ratio of phase $\alpha$ to the standard phase. Q85RNF offers two methods to determine the RIR. One method uses the actual relative intensity as measured to determine the RIR. The second method uses input relative intensity values (in this case the average relative intensity reported in Table 10, from all 16 bottles) to calculate the RIR. Both methods were employed and the results appear in Tables 11 and 12 , respectively.

As a final test for homogeneity and to establish the percent amorphous content eight of the sixteen samples were tested using the method of additions. AUTO again requested a runfile which designated the amorphous intervals to be scanned as well as the high and low background angles and approximate peak positions for the reference lines. The minimum acceptable error in net integrated intensities was one percent with a maximum counting time of 10 minutes. For each sample, AUTO requested the weight fraction of spiking material added to 1.0 grams of starting powder. This runfile was then used to collect the data for all the samples (from each of eight 


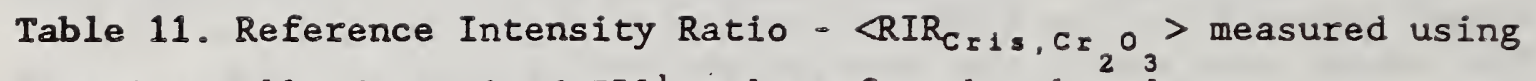
experimentally determined $I^{x}{ }^{1}$ values for that bottle

AK-1

\begin{tabular}{llll}
\hline $\begin{array}{l}\text { BOTILE } \\
\text { NUMBER }\end{array}$ & RIR & RMS $^{*}$ & $\begin{array}{l}\text { BOTT } \\
\text { NUMB }\end{array}$ \\
10 & 3.0194 & .0177 & 10 \\
50 & 3.3789 & .0485 & 69 \\
69 & 3.4079 & .0396 & 104 \\
92 & 2.9848 & .0361 & 104 \\
126 & 3.0521 & .0269 & 126 \\
154 & 3.0306 & .0400 & 187 \\
165 & 3.0667 & .0181 & 187 \\
211 & 2.8431 & .0325 & 211 \\
211 & 2.8296 & .0767 & 282 \\
227 & 2.9943 & .0278 & 304 \\
253 & 2.7902 & .0142 & \\
274 & 2.9853 & .0582 & \\
282 & 3.4164 & .0744 & \\
304 & 3.3107 & .0652 & \\
& & &
\end{tabular}

AM-2

BOTTLE
NUMBER

$\begin{array}{ll}2.9327 & .0081 \\ 3.0594 & .0201 \\ 3.2814 & .0322 \\ 3.3096 & .0418 \\ 3.1567 & .0061 \\ 2.9131 & .0100 \\ 3.0700 & .0154 \\ 2.7930 & .0127 \\ 3.2483 & .0344 \\ 3.5294 & .0101\end{array}$

$\begin{array}{ll}\mathrm{ALI} & 3.10 \\ \mathrm{SD}^{\star \star} & 0.21\end{array}$

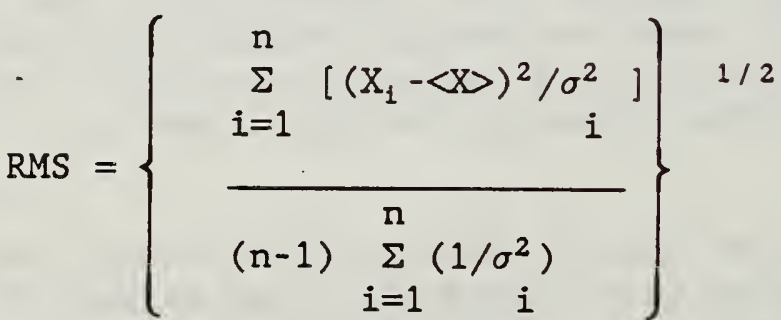

$$
\begin{aligned}
& \mathrm{n}=\text { number of measurements }
\end{aligned}
$$

The RMS estimate is weighted by $\sigma_{i}$ the estimated standard deviation of the observation $x_{1}$ based on counting statistics which were kept low compared to the expected variations.

** SD is the standard deviation from the average value (ALL). 


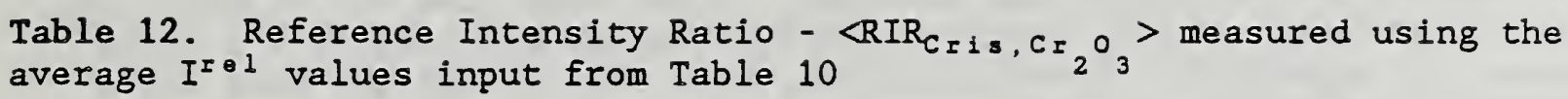

\begin{tabular}{|c|c|c|c|c|c|}
\hline \multirow[b]{2}{*}{$\begin{array}{l}\text { BOTTLE } \\
\text { NOMBER }\end{array}$} & \multicolumn{2}{|l|}{$A M-1$} & \multirow[b]{2}{*}{$\begin{array}{l}\text { BOTTLE } \\
\text { NUMBER }\end{array}$} & \multicolumn{2}{|c|}{$A M-2$} \\
\hline & $\mathbf{R I R}$ & RMS & & RIR & RMS \\
\hline 10 & 3.1160 & .0381 & 10 & 3.0039 & .0336 \\
\hline 50 & 3.5289 & .0645 & 69 & 3.2395 & .0562 \\
\hline 69 & 3.5197 & .0595 & 126 & 3.1846 & .0342 \\
\hline 92 & 3.1615 & .0594 & 187 & 2.9736 & .0351 \\
\hline 126 & 3.1372 & .0456 & 187 & 3.0607 & .0315 \\
\hline 154 & 3.0531 & .0436 & 211 & 2.8021 & .0216 \\
\hline 165 & 3.1050 & .0408 & 282 & 3.3449 & .0681 \\
\hline 211 & 2.9154 & .0745 & 304 & 3.5879 & .0210 \\
\hline 211 & 3.0096 & .0785 & & & \\
\hline 227 & 3.0318 & .0600 & & & \\
\hline 253 & 2.7914 & .0364 & & & \\
\hline 274 & 2.9540 & .0513 & & & \\
\hline 282 & 3.5409 & .0840 & & & \\
\hline 304 & 3.5278 & .0793 & . & & \\
\hline ALI & 3.16 & & & . & \\
\hline SD & 0.24 & & & & \\
\hline
\end{tabular}


bottles). Quartz powder ground from a single optical grade crystal to less than $40 \mu \mathrm{m}$ was used to determine the background intensity under the amorphous areas. First a very slow $x$-ray powder pattern of quartz $\left(1 / 8^{\circ} 2 \theta\right.$ per minute) was collected and examined. Areas less than $40^{\circ} 2 \theta$ which did not include peak or tail intensity were collected and read into a least square fit algorithm. In this case the best fit through the data was a straight line although the program was equipped to fit non-linear functions to the data. The program fitted the best curve through the data and produced as an output file a continuous background curve. The intensities measured at the $2 \theta$ values of the simulated quartz background corresponding to the $2 \theta$ values of the designated amorphous regions in cristobalite were used to establish the instrumental background under the amorphous regions by Q85AMR (part of the NBS*QUANT84 package). The results from the eight samples, each spiked three times (Table 13) show that the percent amorphous content is between 0 and 3 percent.

Two samples of cristobalite, 187 and 126 were washed in hot orthophosphoric acid. After this acid treatment the RIR's and weight percent amorphous were remeasured. These results appear in Table 14.

\section{DISCUSSION: Tests for Homogeneity}

The chemical analysis of the as-received cristobalite is indicative of a relatively pure cristobalite. Inhomogeneities or impurities in great enough quantity would be detected as added, unidentified reflections in the cristobalite pattern by $\mathrm{x}$-ray phase analysis. Lattice imperfections or chemical inhomogeneities would be detected as changes or variability in lattice constants and to a lesser degree as changes in relative intensities.

The Guinier de Wolff camera is often used for trace phase detection. Analysis of the Guinier camera film as well as the $x$-ray diffractometer trace (Figure 2) did not reveal any reflections not accounted for by cristobalite. Thus, the cristobalite was characterized as "x-ray pure" and ready for the second phase of analysis.

Tables 5-9 report the lattice parameters, a value $\sigma$ (the estimated standard deviation from least squares refinement of 35 or 36 reflections), and SD (the standard deviation of measured lattice parameters from the average). The lattice parameter studies indicate some probability of bottle to bottle variability based on the larger standard deviation (SD) value for the 16 bottles (Table 5) in comparison with the SD value observed in measurement reproducibility (Tables 6-9). The possible variability, however, is quite small and should have no observable effect on the certified percent crystalline content. No systematic correlation between lattice parameter and analyzed weight percent amorphous exists, as shown in Figures 4 and 5 .

The results of the relative intensity measurements (Table 10) show that the average values of each reflection less than $50^{\circ} 2 \theta$ are very reproducible and in very good agreement with calculated integrated relative intensity values. It should be noted here that the calculated cristobalite patterns from data reported by Dollase ${ }^{17}$ and by Peacor ${ }^{18}$ are essentially identical. A much larger difference in the calculated pattern results by 
Table 13. Amorphous Content in Cristobalite Determined by Modified Method of Additions, Using Ground Quartz for Background Approximation

\begin{tabular}{|c|c|c|c|c|c|c|}
\hline BOTTLE & REFERENCE & & AT PERCENT & AMORPHOUS & & \\
\hline NUMBER & LINE & AREA1 & AREA2 & AREA3 & ALL & RMS \\
\hline 10 & ALI & 0.90 & 1.60 & 2.49 & 1.66 & 0.69 \\
\hline 69 & ALL & 0.66 & 1.44 & 2.20 & 1.43 & 0.67 \\
\hline 92 & ALL & 2.35 & 2.37 & 3.49 & 2.74 & 0.57 \\
\hline 126 & ALL & 0.26 & 1.32 & 1.72 & 1.10 & 0.65 \\
\hline 165 & AIL & 2.15 & 1.93 & 3.59 & 2.56 & 0.78 \\
\hline 187 & ALL & 1.44 & 2.07 & 2.88 & 2.13 & 0.63 \\
\hline 211 & ALL & 1.98 & 1.90 & 3.48 & 2.45 & 0.77 \\
\hline 304 & ALL & 1.29 & 1.80 & 2.67 & 1.92 & 0.61 \\
\hline ALL & ALL & 1.38 & 1.80 & 2.82 & 2.00 & \\
\hline SD & ALL & 0.70 & 0.32 & 0.63 & 0.54 & \\
\hline
\end{tabular}


Table 14. Amorphous Weight Fraction and RIR Constant of Acid Washed Samples 126 and 187

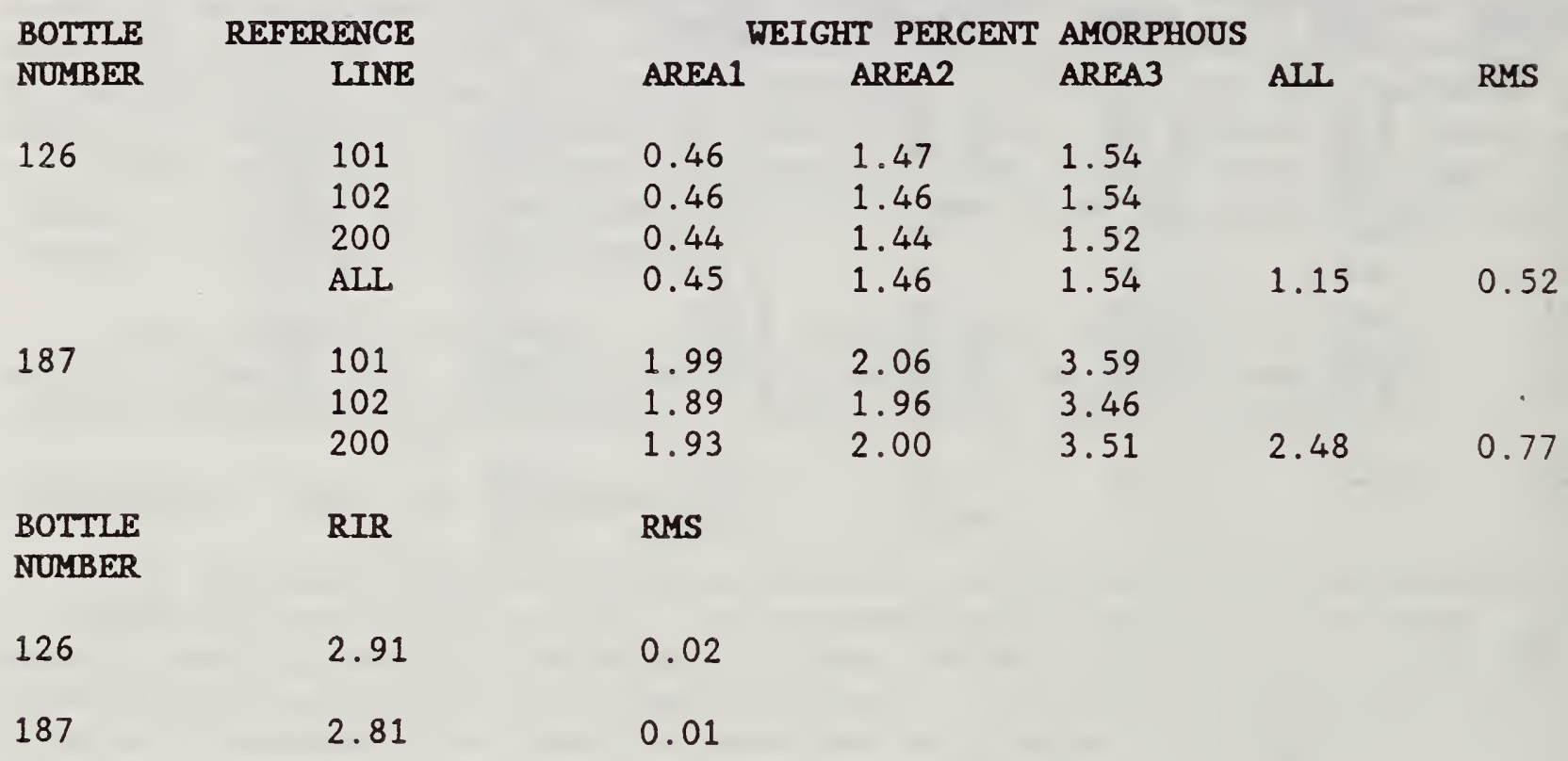




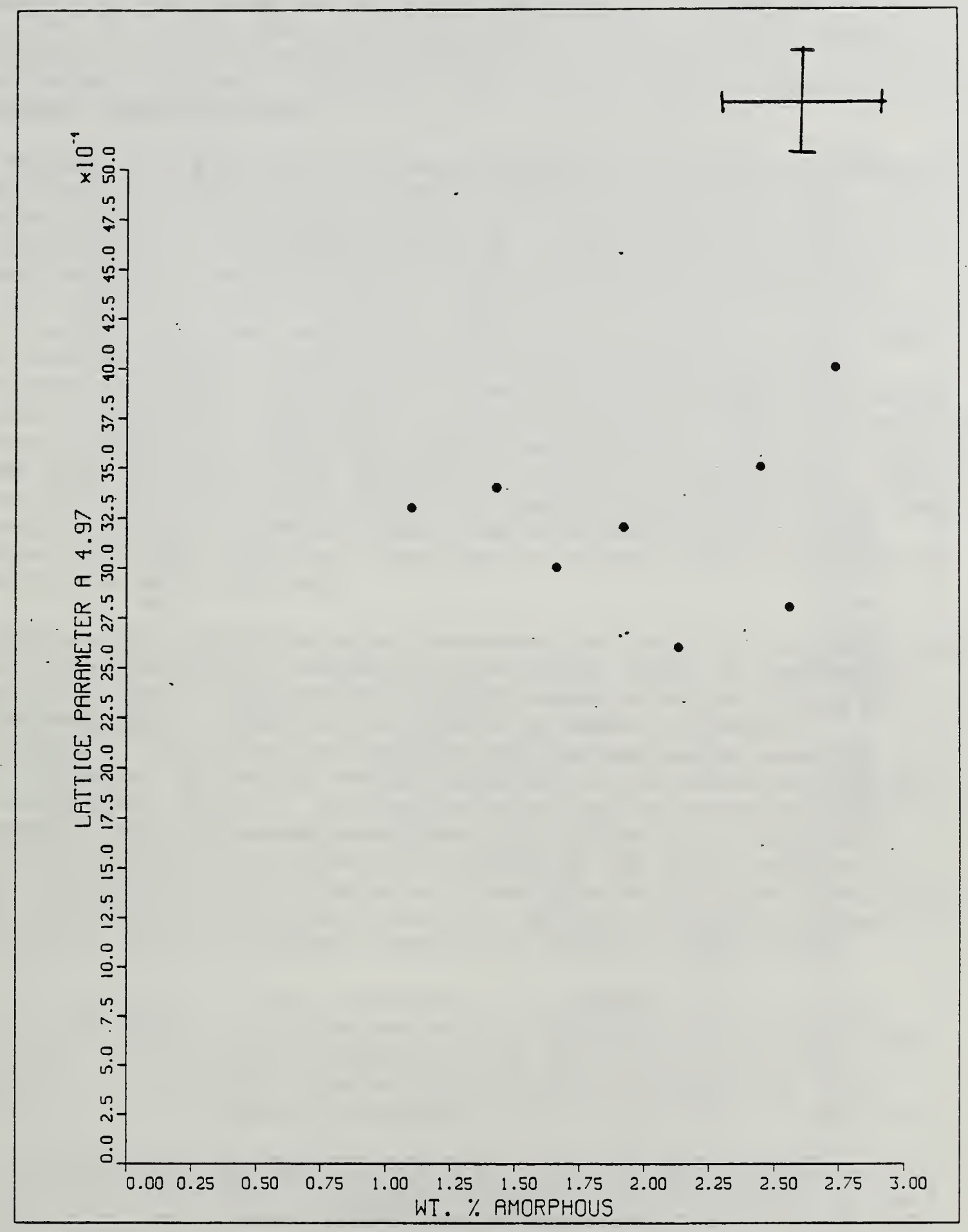

Figure 4. Lattice Constant a (in $\dot{A}$ ) versus Weight Percent Amorphous for 8 Samples of Cristobalite. Error bars indicate $2 \sigma$. 


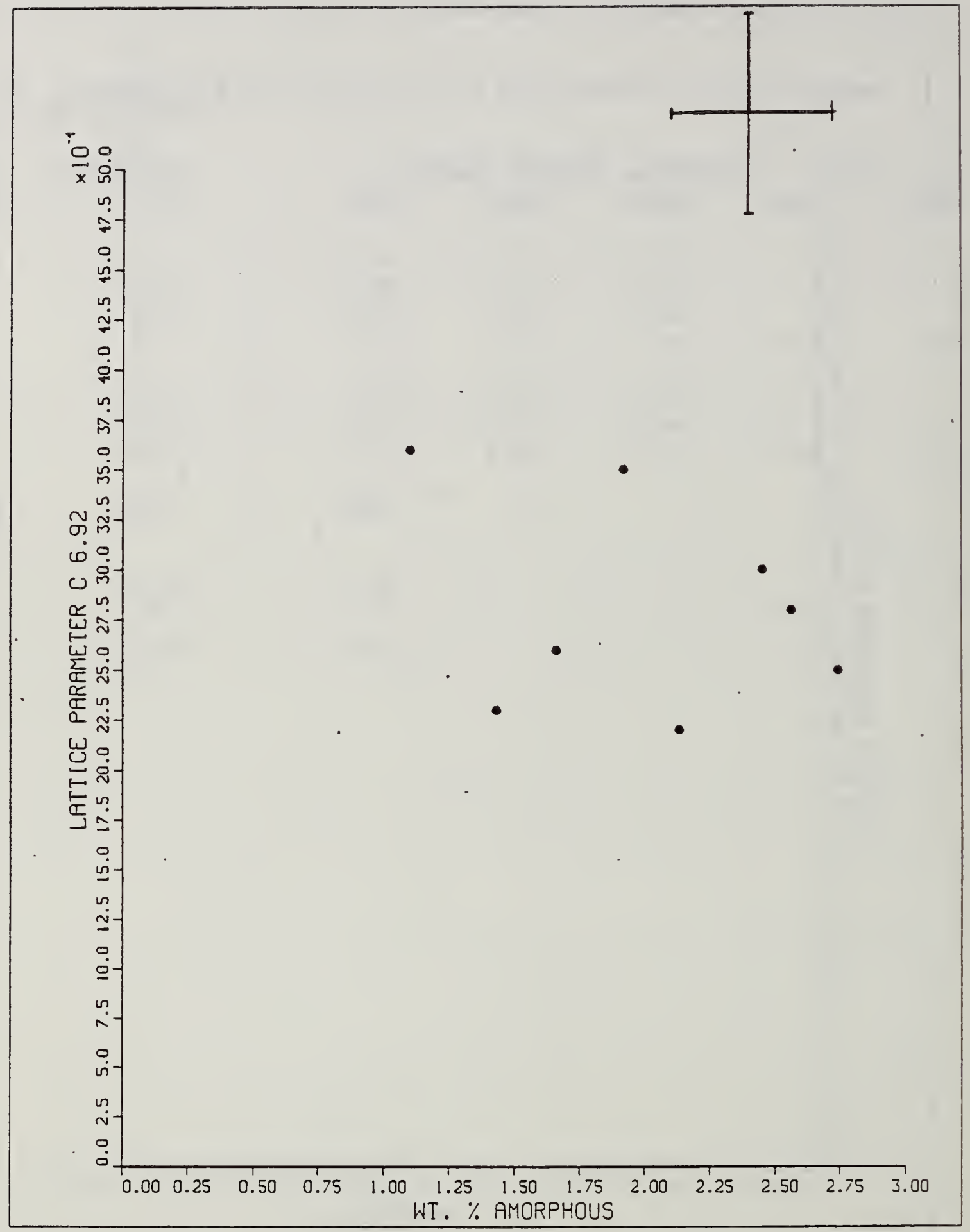

Figure 5. Lattice Constant $c$ (in $\dot{A}$ ) versus Weight Percent Amorphous for 8 Samples of Cristobalite. Error bars indicate $2 \sigma$. 
changing the ionic nature of the cristobalite atoms, Table 10. Relative intensities were obtained for the $(110),(201),(211)$, and (202)

reflections, however the values for these four very weak peaks were not certified because the error in the net integrated intensity due to counting statistics was greater that the acceptable 18 error. No instrumental variability in measured relative intensities is evident based on the <RI> and SD values reported in Table 10. That is, all values seem to be within measurement reproducibility.

Preferred orientation also causes variability in measured intensities, which in turn will affect quantitative $x$-ray diffraction analysis. It is relatively simple to determine whether or not preferred orientation is having an effect on intensity measurement. Samples from bottles 211 and 282 were mounted by methods which attempt to orient the sample, and relative intensities were measured. The results of Table 15 show that by simply packing the pure, undiluted sample into the cavity of the sample holder and pressing to a smooth surface produces measured relative intensities which are comparable to those obtained by methods minimizing preferred orientation. The sample which was mixed with distilled water and dried on a glass slide shows much greater variability. Closer examination of this data shows that this variability is due to a transparency affect; the sample is too thin and the incident beam penetrates through the sample to the glass slide. As $2 \theta$ increases, the penetration of the $x$-rays increases and there should be a decrease in intensity with increasing $2 \theta$, as is the case with this data.

Optical and scanning electron microscopy analysis of the cristobalite powder showed irregularly shaped particles which tended to agglomerate (Figure 6). However agglomeration tended toward spherical shapes which is what methods such as spray drying utilize to reduce preferred orientation ${ }^{1}$. From the $x$-ray analyses and the microscopy examination of shape, preferred orientation was not expected to contribute uncertainty to the quantitative analysis. No further techniques to minimize preferred orientation were implemented based upon this observation. Since all bottles were judged to be effectively identical and since quantitative analysis depends upon the integrated intensities of specified reflections, the possible bottle to bottle variability detected by lattice parameter measurements should not affect quantitative analyses appreciably.

The combination of the qualitative $x$-ray results, particle size analysis and density determinations with preliminary x-ray diffraction results and chemical analysis indicate that the lot of cristobalite is homogeneous, to the extent that no significant inhomogeneities exist relative to the precision of the quantitative analyses of this material.

The experimentally determined RIR in Tables 11 and 12 , was greater than the calculated value. The calculated value was obtained from the $I_{C \text { Is }} / I_{C o r u n d u m}$ value calculated by POWD12 divided by the reported $I / I_{C o I}$ value reported for the $\mathrm{Cr}_{2} \mathrm{O}_{3}$ of the intensity set SRM 674 . Unlike the calculated value, $I_{C_{r i s}} / I_{C_{0} r}$, which is free from the effects of extinction, preferred orientation and microabsorption, the $I / I_{C o}$ value reported for SRM $674-\mathrm{Cr}_{2} \mathrm{O}_{3}$ was an experimentally determined constant, 2.1. The latter may or may not be free from the effects of extinction and microabsorption and thus constitutes a probable source of error. Thus reliable crystal 
Table 15. Relative Intensity Data - Test for Preferred Orientation

$\begin{array}{llllllllllll}\begin{array}{l}\text { BOTTLE } \\ \text { NUMBER }\end{array} & 101 & 110 & 111 & 102 & 200,112 & 201 & 211 & 202 & 113 & 212 \\ 282^{*} & 100 & .59 & 8.83 & 11.22 & 18.51 & .19 & 2.82 & 2.71 & 5.27 & 5.58 \\ 282^{* *} & 100 & .55 & 8.11 & 9.99 & 15.55 & .16 & 2.10 & 2.05 & 3.93 & 3.96 \\ 211^{*} & 100 & .63 & 8.68 & 11.3 & 18.88 & .18 & 2.82 & 2.70 & 5.38 & 5.63 \\ \text { ALL * * }^{*} & 100 & .50 & 8.7 & 10.8 & 17.5 & .20 & 2.8 & 2.5 & 5.0 & 5.1\end{array}$

" Indicates a "packed" mount as described in text.

* Indicates a glass slide mount.

*** ALL is the average certified relative intensity from Table 10. 

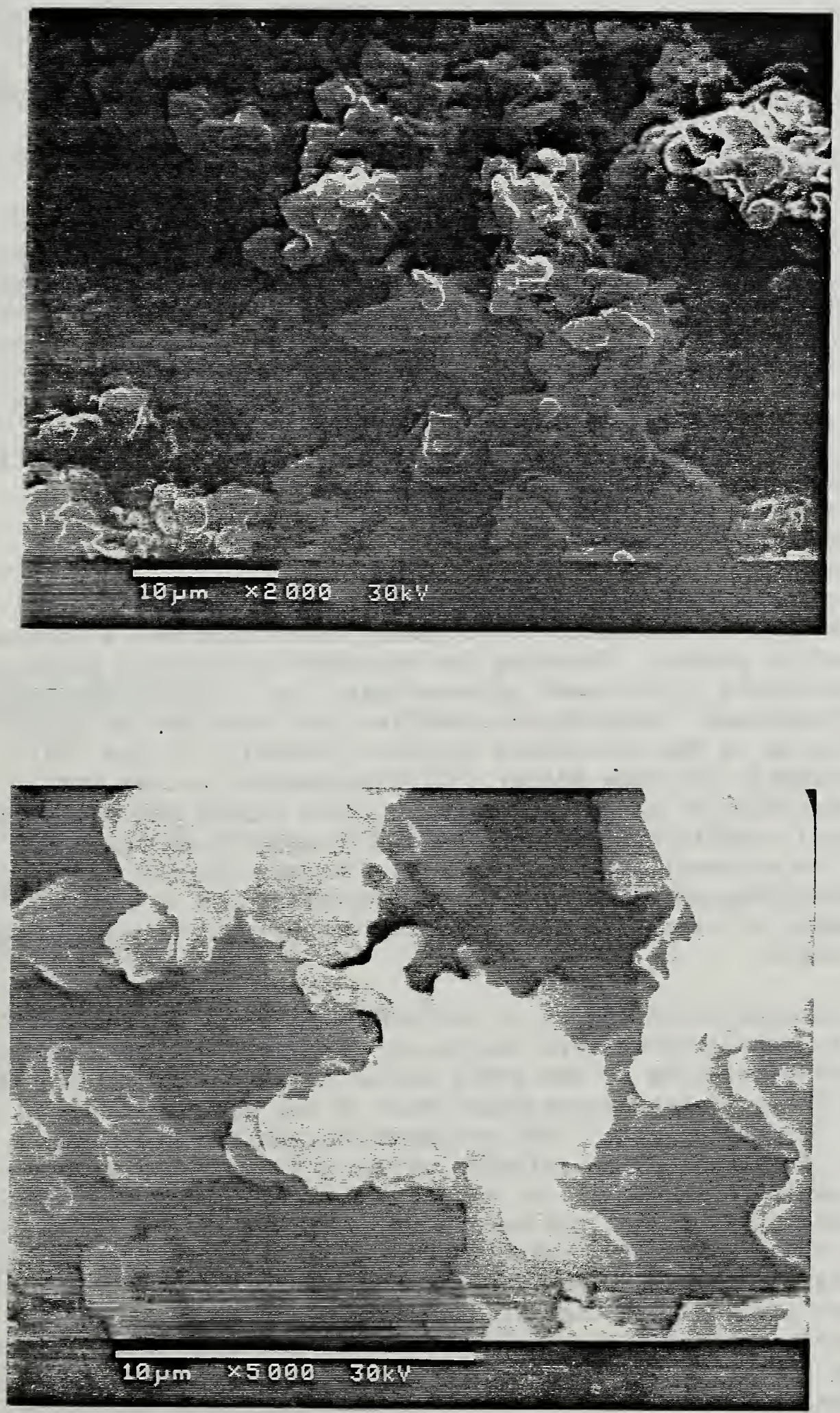

Figure 6. Scanning Electron Micrographs of Cristobalite Sample 211 at Magnifications of $2000 \mathrm{X}$ and 5000X. 
structure data22,23 was obtained and used to calculate the $I / I_{C \circ r}$ value for $\mathrm{Cr}_{2} \mathrm{O}_{3}$. Based upon the input data of Table 16, POWD12 calculated an $\mathrm{I} / \mathrm{I}_{\mathrm{C} o x}$ value of 2.2; very close to the reported experimental value of $2.1 \pm .05$. The discrepancy between the experimentally determined $I_{C_{\text {I }} s} / I_{C_{2203}}$ and the "calculated" value may be due to the effect of extinction, microabsorption or preferred orientation or a combination of these effects. Thus, the calculated RIR could not be used to determine the amount of amorphous silica present in the cristobalite.

Secondary extinction is an effect caused by strongly scattering, but imperfect crystallites. During diffraction crystallites oriented properly diffract $x$-rays at the Bragg angle. Those crystallites near the surface reduce the effective intensity of the incident beam for crystallites deeper in the sample. The diffracted beam may likewise be reduced in intensity by secondary scattering as it leaves the sample. The combination of these effects acts to reduce the recorded intensity of reflections (acts to increase the apparent absorption coefficient of the material). This effect is much more pronounced for strong reflections than for weak one $s^{9}$. Pronounced extinction effects have been shown to affect quantitative analysis by as much as 50 percent ${ }^{21}$.

Because of the possible influence of extinction on intensity measurements we sought to determine if secondary extinction was a problem with the cristobalite powder. Checking for secondary extinction requires monitoring the intensity of the most intense peak, the (101) reflection of cristobalite in this case, relative to a smaller peak such as the (102) peak and comparing it to the calculated relative intensity of the (101) reflection converted to the same scale. All experimental values were compared to the calculated values because calculated values reflect ideal (extinction - free) conditions. If all the sample conditions were identical, then the extinction effect would be the same for all bottles. However, the orientation and size of crystallites could not be held constant from sample to sample so if extinction was present it would vary from sample to sample.

First, the integrated intensity of the (101) reflections from the relative intensity measurements were monitored; that is, the intensity of the (101) reflection relative to the (102) reflection was calculated, Table 17. The data in Table 17 represents conversion of the data in Table 10 to the new relative intensity scale. The resultant variability in the intensity of the (101) reflection relative to the (102) reflection ranges from 914.2 for sample 187 to 953.9 for sample 227 (Table 17), which lies within the standard deviation of the measurement. The average relative intensity of the (101) reflection relative to the (102) reflection is 933 which is approximately three percent greater than the calculated value of 909 and 11 percent greater than the calculated value of 833 . There is little discrepancy between the average experimental and calculated values. If extinction was affecting the intensity measurements then there would be a much greater variability in the intensity of the (101) peak than of a weaker peak such as the (102) reflection. Reproducibility of the relative intensity measurements for sample 10 (Tables 10 and 17) indicate that the (101) peak and the (102) peak show approximately equal variations in intensity. Note that this includes any mounting and instrumental variabilities already present. 
Table 16. Input Data for POWD12 - Calculated Patterns of Cristobalite and $\mathrm{Cr}_{2} \mathrm{O}_{3}$

\section{CRISTOBALITE DATA}

REFERENCE

(Dollase, 1965) 16

(Peacor, 1973) 17

CRYSTAL SYSTEM

Tetragonal

Tetragonal

SPACE GROUP

$\mathrm{P}_{1} 2_{1} 2$

$\mathrm{P}_{1} 2_{1} 2$

IATTICE PARAMETERS

$a=b=4.978$
$c=6.948$
$\alpha=\beta=\gamma=90.0^{\circ}$

$\mathbf{a}=\mathbf{b}=4.978$

$c=6.948$

$\alpha=\beta=\gamma=90.0^{\circ}$

ATOMIC POSITIONS

Si

$\mathrm{x}=\mathrm{y}=0.30004$

$z=0.0$

Si

0

$x=0.23976$

$\mathrm{y}=0.10324$

$z=0.17844$

$\mathrm{x}=\mathrm{y}=0.3002$

$z=0.0$

Si

$\beta($ iso $)=0.83$

0

$\beta($ iso $)=1.55$

0

$\mathrm{x}=0.2394$

$\mathrm{y}=0.1049$

$z=0.1785$

VALUE OF ISOTROPIC TEMPERATURE FACTOR

REFERENCES

(Finger and Hazen, 1980) 22 ; (McMurdie, et al., 1987)23

CRYSTAL SYSTEM

Trigonal

SPACE GROUP

R3C

LATTICE PARAMETERS

$$
\begin{aligned}
& a=b=4.95876 \\
& c=13.5942 \\
& \alpha=\beta=90.0^{\circ} \\
& \gamma=120.0^{\circ}
\end{aligned}
$$

ATOMIC POSITIONS

$\mathrm{Cr}$

$$
\begin{aligned}
& x=y=0 \\
& z=0.34766 \\
& 0 \\
& x=0.3051 \\
& y=0.0 \\
& z=0.25
\end{aligned}
$$

VALUE OF ISOTROPIC

$\mathrm{Cr}$

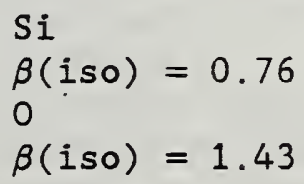

TEMPERATURE FACTOR

$\beta$ (iso $)=0.25$

0

$\beta($ iso $)=0.28$ 
Table 17. Relative Intensity Data from Table 10 Converted to $I^{R \cdot 1}(102)=$ 100 Scale

BOTTLE NUMBER

AM-2

10

10

23

50

69

92

104

126

154

165

187

211

AM-1

227

253

274

282

304

ALL

SD

CALCULATED

$I^{R} \in 1$ *

$I^{R \otimes 1 * *}$
HKI.

101

933.4

948.3

932.7

957.6

915.4

934.8

928.8

926.5

946.9

924.9

914.2

929.1

$\begin{array}{ll}953.9 & 100.0 \\ 929.6 & 100.0 \\ 931.2 & 100.0 \\ 927.6 & 100.0 \\ 926.2 & 100.0 \\ 933.0 & 100.0\end{array}$

11.8

833

909
102

100.0

100.0

100.0

100.0

100.0

100.0

100.0

100.0

100.0

100.0

100.0

100.0
100.0

100

100 
The data in Table 18 represent conversion of the raw data used to calculate the RIR in Table 11 to the new relative intensity scale. The resultant variability in the intensity of the (101) reflection relative to the (102) reflection ranges from 811.7 for sample 282 to 983.2 for sample 253. This also includes any variability introduced by different mounting methods and different instruments. The average relative intensity of the (101) reflection is 924.8 , which is only two percent greater than the calculated value of 909 and ten percent greater than the average value of 833. This variability lies well within the variability in relative intensity measurements when different mounting methods and instruments were employed. There seems to be no extinction effect in the cristobalite.

The particle size distribution data of Table 2 lend further support to the assumption that secondary extinction is not having an effect on the intensities of the cristobalite reflections. Because the total diffracted intensity from crystallites depends on its volume, secondary extinction does not generally occur for fine powders with particle sizes less than 10 $\mu \mathrm{m}$. Inspection of the particle size distribution of cristobalite in Table 2 shows that less than 5 percent by mass of the particles are larger than 10 $\mu \mathrm{m}$ and even that 5 percent is suspect due to the high degree of agglomeration that occurs with the cristobalite.

The experimental RIR should vary with the crystallinity of a sample and therefore could be used as a check on the direct determination of amorphous content by the modified method of additions technique. Comparison of the RIR data in Table 17 with the amorphous spike data in Table 13 shows that the RIR constant is relatively insensitive to small fluctuations in percent amorphous. The relationship plotted in Figure 7 shows that all the data lies within the relative error of both measurements. In general, the percent amorphous data indicates a low variability in amorphous content.

\section{DISCUSSION: Analysis of Amorphous Content}

The effects of extinction, microabsorption and preferred orientation have a profound effect on measured integrated intensities and are very hard to isolate. Methods such as the internal standard method which rely upon calibrating standards for quantitative analysis are often affected because it is hard to hold the effects of extinction, crystallite size and absorption constant for calibrating materials and the actual sample. The possibility that these effects will occur is eliminated when using the method of additions because this type of analysis does not require calibration standards. Thus quantitative techniques for the $x$-ray diffraction determination of the amorphous content in cristobalite which rely upon the internal standard method for analysis while ideally possible are difficult to implement in practice.

The method of additions for quantitative determination of the amorphous weight fraction in cristobalite is inherently a more reliable technique than the internal standard method for this analysis. The method can be modified by choosing to add an amorphous phase to the cristobalite rather than a crystalline phase such that it is a direct technique for determining the amorphous weight fraction. Secondly, changes in the 


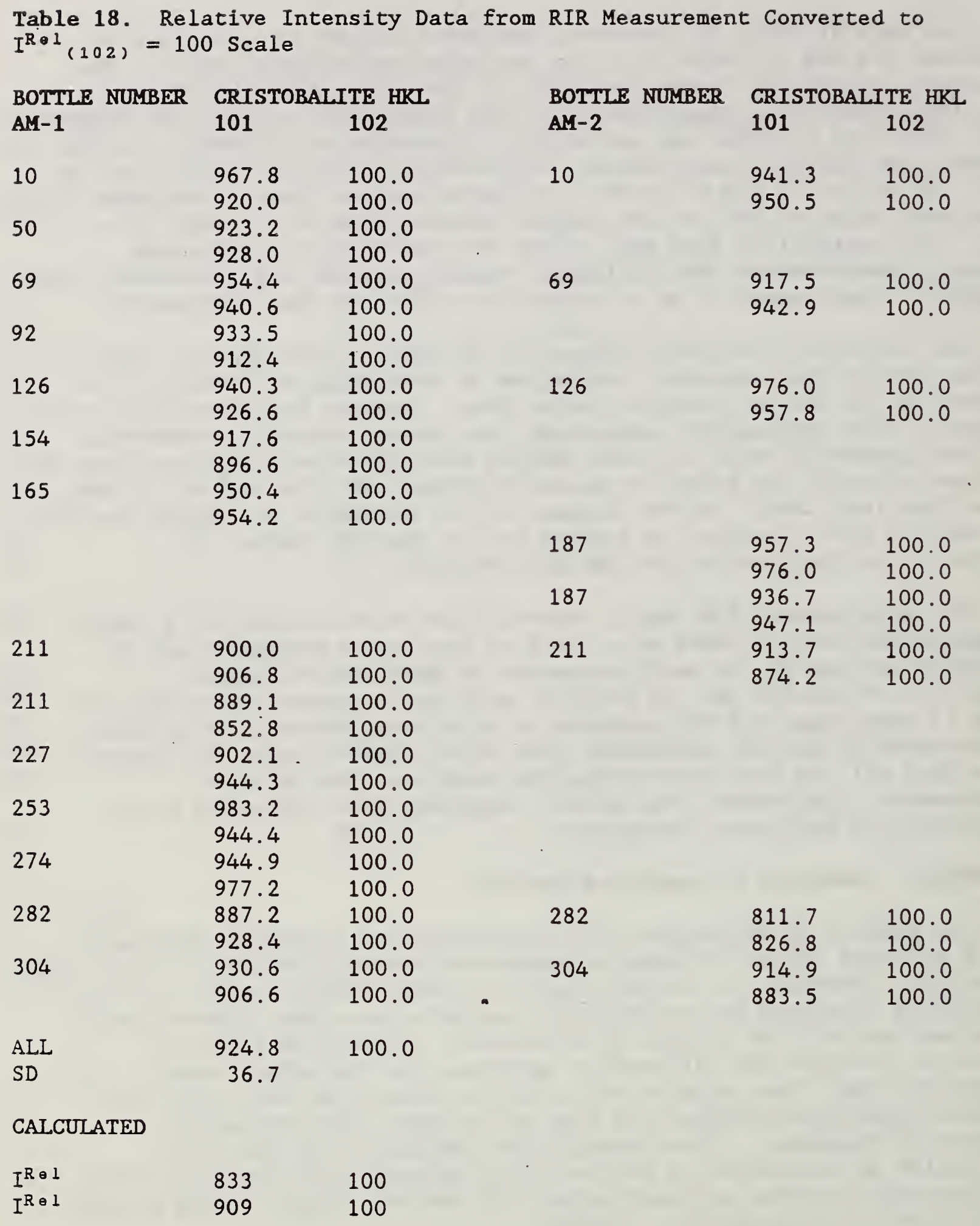




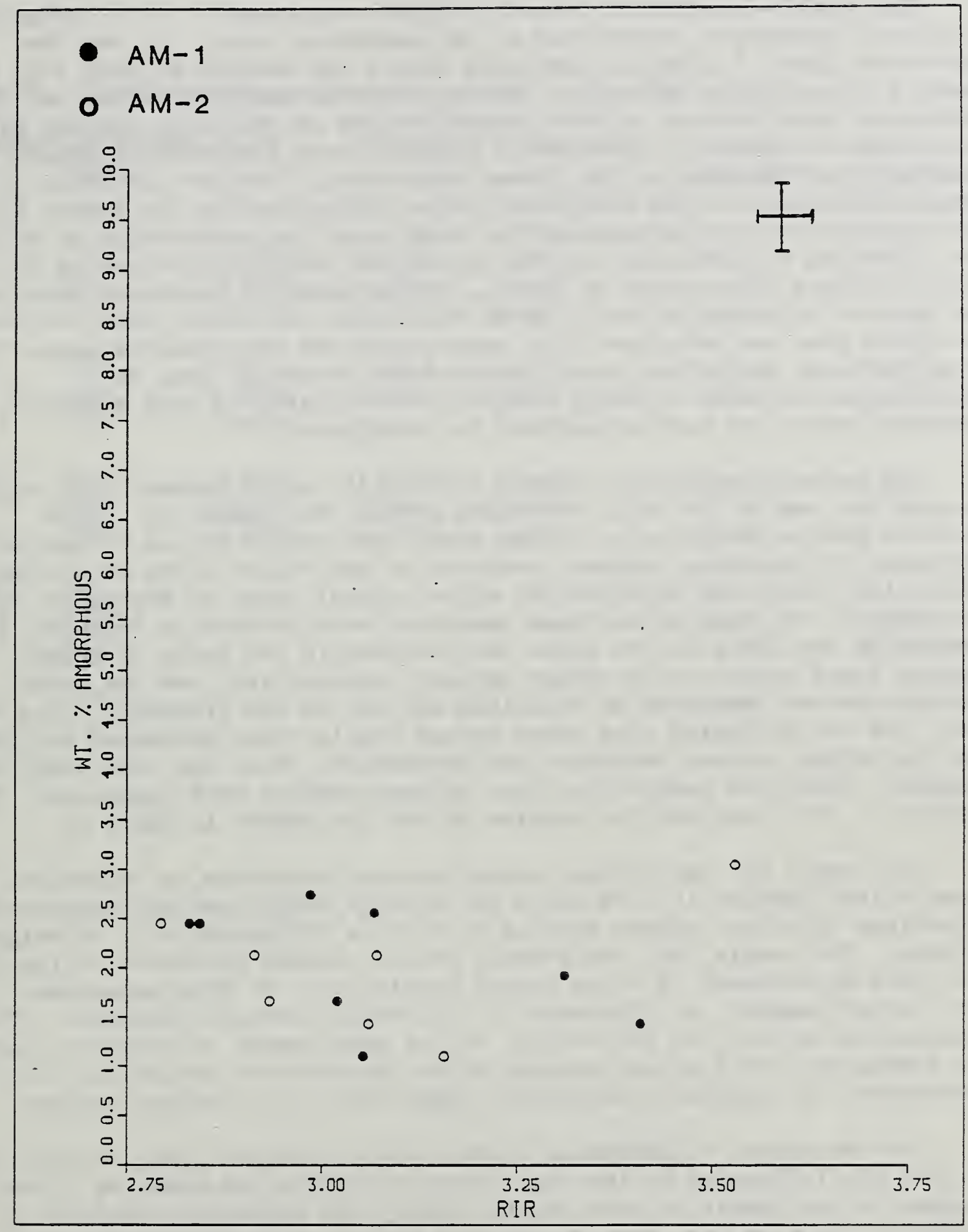

Figure 7. Weight Percent Amorphous versus RIR Constant for 8 Samples of Cristobalite. Error bars indicate $2 \sigma$. 
effects of microabsorption are diminished because the absorptive powers of cristobalite and fused silica are approximately equal.

The modified additions method requires measurement of the background corrected integrated intensities of the amorphous areas, $I_{1 \alpha}$ and the reference lines, $I_{j \beta}$ for an undiluted sample and samples diluted with known amounts of amorphous material. The use of three amorphous areas and three reference lines results in nine determinations of amorphous content per sample of cristobalite. The use of three diluted mixtures per sample permits error analysis of the linear regression. The data in Table 19 is a complete analysis of the amorphous content determination for sample 126 . The amorphous content determined for each area/line combination as well as the slope and $y$ - intercept of the regression line are reported in this table. Figure 8 is a plot of $I_{i \alpha} / I_{j \beta}$ versus grams of amorphous spike added per gram of cristobalite which shows the linear fit of the data for each amorphous area and reference line combination for cristobalite sample 126. No significant deviations from linearity are observed; thus the experimental evidence strongly supports the validity of this modified method of additions and corrections for background.

The measured amorphous content (Table 13) varied between 1.10 weight percent for sample 126 and 2.74 weight percent for sample 92 . This prompted further exploration of the data. Is there a bottle to bottle variation in amorphous content predicted by the values above or do these values lie within the experimental error, actual level of detection, of the techniques? The answers to these questions were pursued as follows. For samples 92 and 304 a fourth spike was prepared in the ratio 30 weight percent fused quartz to 70 weight percent cristobalite, and the $x-r a y$ intensities were measured as described earlier in the procedure. The $x$-ray data from the undiluted plus three spiked samples were processed by Q85AMR and the weight percent amorphous was determined. Next the data from the original, undiluted sample plus four diluted samples were processed. The results of this analysis for samples 92 and 304 appear in Table 20.

For sample 92, the average weight percent amorphous as determined with three spiked samples is 1.98 while the average weight percent amorphous as determined with four spiked samples is 2.74 , a difference of 0.76 weight percent. For sample 304, the average weight percent amorphous varies from 1.52 from measurement of three spiked samples to 1.92 from measurement with four spiked samples, a difference of 0.40 weight percent amorphous. The standard deviation from the average of the measurement of amorphous content for sample 92 is 0.9 weight percent while the standard deviation of the measurement of amorphous content for sample 304 is 0.3 weight percent.

The two values of amorphous content are determined from the same data so they are influenced by the same errors in mixing and mounting. What changes is the number of data points used by the regression analysis to determine the best line through the data and to extrapolate to the $x$ intercept, which is the weight fraction amorphous in the original material. Measurement of the undiluted sample and one diluted sample is enough for the linear regression analysis to establish a line and extrapolate to the value of amorphous content in the original material. However, the accuracy of the method should increase with the number of diluted samples. Thus, comparison of the two values of amorphous content for the same bottle is 
Table 19. Estimated Errors for Analysis of Sample 126

\begin{tabular}{|c|c|c|c|c|c|c|}
\hline $\begin{array}{l}\text { AMORPHOUS } \\
\text { AREA }\end{array}$ & $\begin{array}{l}\text { REFERENCE } \\
\text { LINE }\end{array}$ & SLOPE & INTERCEPT & CORRELATION & $\begin{array}{l}\text { WEIGHT } \\
\text { PERCENT }\end{array}$ & $\begin{array}{l}\text { LEAST } \\
\text { SQUARES } \\
\text { ESD* }\end{array}$ \\
\hline $\begin{array}{ll}\text { Area } & 1 \\
\text { Area } & 2 \\
\text { Area } & 3\end{array}$ & $\begin{array}{l}101 \\
101 \\
101\end{array}$ & $\begin{array}{l}0.2819 \\
0.0898 \\
0.0866\end{array}$ & $\begin{array}{l}0.0009 \\
0.0012 \\
0.0016\end{array}$ & $\begin{array}{l}1.000 \\
1.000 \\
1.000\end{array}$ & $\begin{array}{l}0.32 \\
1.39 \\
1.79\end{array}$ & $\begin{array}{l}0.19 \\
0.12 \\
0.17\end{array}$ \\
\hline $\begin{array}{ll}\text { Area } & 1 \\
\text { Area } & 2 \\
\text { Area } & 3\end{array}$ & $\begin{array}{l}102 \\
102 \\
102\end{array}$ & $\begin{array}{l}2.6253 \\
0.8364 \\
0.8068\end{array}$ & $\begin{array}{l}0.0062 \\
0.0107 \\
0.0135\end{array}$ & $\begin{array}{l}0.999 \\
1.000 \\
1.000\end{array}$ & $\begin{array}{l}0.23 \\
1.28 \\
1.68\end{array}$ & $\begin{array}{l}0.25 \\
0.07 \\
0.21\end{array}$ \\
\hline $\begin{array}{ll}\text { Area } & 1 \\
\text { Area } & 2 \\
\text { Area } & 3\end{array}$ & $\begin{array}{l}200 \\
200 \\
200\end{array}$ & $\begin{array}{l}1.5501 \\
0.4938 \\
0.4763\end{array}$ & $\begin{array}{l}0.0037 \\
0.0063 \\
0.0080\end{array}$ & $\begin{array}{l}1.000 \\
1.000 \\
1.000\end{array}$ & $\begin{array}{l}0.24 \\
1.28 \\
1.68\end{array}$ & $\begin{array}{l}0.21 \\
0.06 \\
0.19\end{array}$ \\
\hline $\begin{array}{ll}\text { Area } & 1 \\
\text { Area } & 2 \\
\text { Area } & 3\end{array}$ & $\begin{array}{l}\text { ALL } \\
\text { ALL } \\
\text { ALL }\end{array}$ & & & & $\begin{array}{l}0.26 \\
1.32 \\
1.72\end{array}$ & $\begin{array}{l}0.05 \\
0.06 \\
0.07\end{array}$ \\
\hline $\begin{array}{l}\text { ALI } \\
\text { RMS }\end{array}$ & ALI & & & & $\begin{array}{l}1.10 \\
0.65\end{array}$ & \\
\hline
\end{tabular}

Least squares ESD is derived from the variances based on the counting statistics. The $\sigma$ reflects both internal consistency and random errors based purely on counting statistics and the propagation of these errors through various computations. 


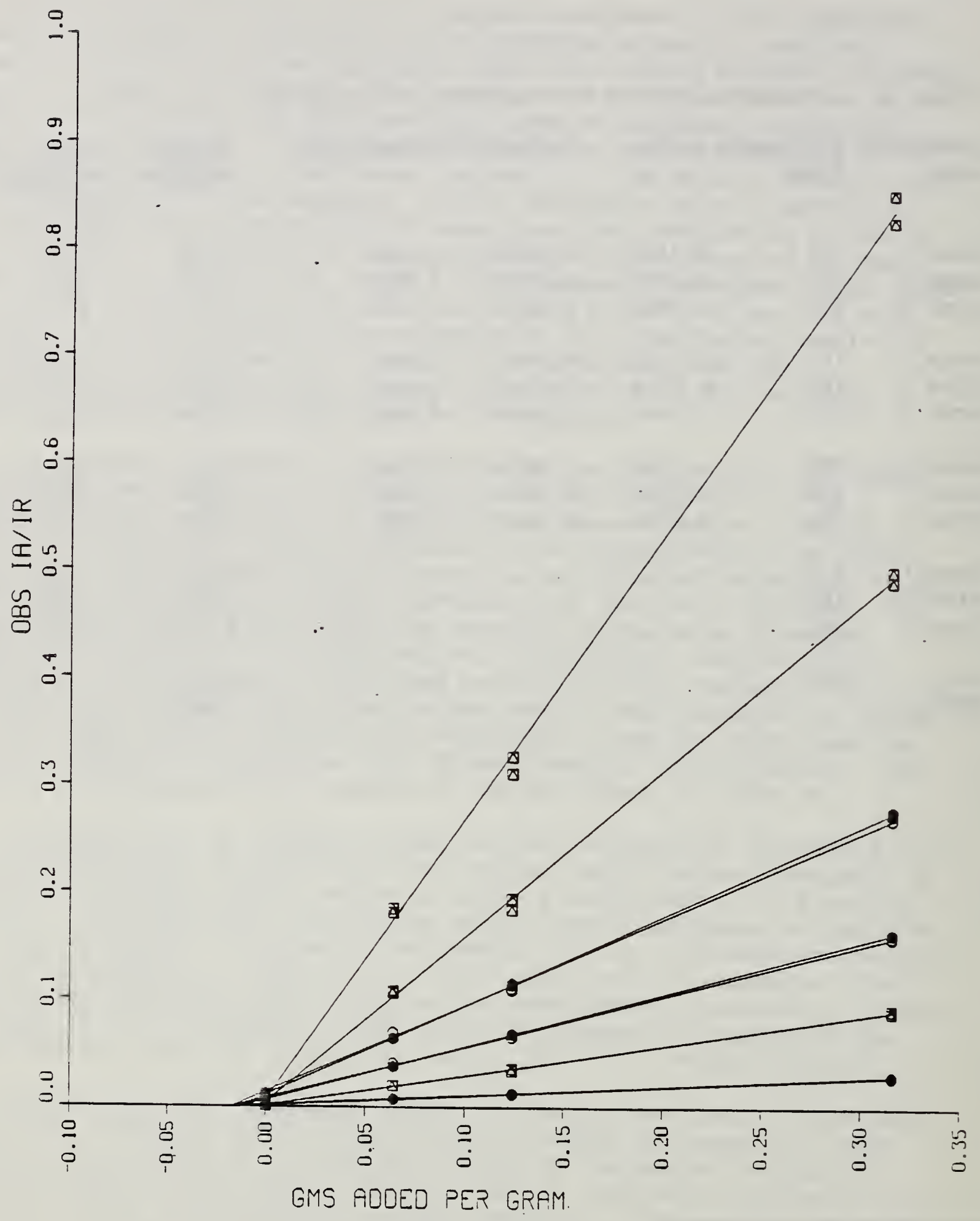

Figure 8. $I_{i \alpha} / I_{j \beta}$ versus Grams of Analyte Added per Gram of Original Material for Amorphous Content Determination in Cristobalite Sample 126. 
Table 20. Results of the Amorphous Content Determination for Samples 92 and 304 using Three and Four Spiked Samples

\begin{tabular}{|c|c|c|c|c|c|c|c|}
\hline BOTTLE & NUMBER & REFERENCE & & WEIGHT PERCENT & AMORPHOUS & & \\
\hline NUMBER & SPIKES & LINE & AREA & 1 AREA 2 & AREA 3 & ALL & RMS \\
\hline 92 & 3 & ALL & 1.29 & 1.91 & 2.75 & 1.98 & 0.64 \\
\hline 92 & 4 & ALL & 2.35 & 2.37 & 3.49 & 2.74 & 0.57 \\
\hline 304 & 3 & ALL & 0.85 & 1.41 & 2.32 & 1.52 & 0.64 \\
\hline 304 & 4 & ALL & 1.29 & 1.80 & 2.67 & 1.92 & 0.61 \\
\hline
\end{tabular}


truly a measure of the accuracy of the modified additions method. The data of Table 20 seems to indicate that at this level of detection (0-5 weight percent amorphous content) the method can be applied with 1.0 weight percent accuracy in the determination, that is, the actual amorphous content for sample 92 is $2.74 \pm 1.0$ weight percent. This standard deviation of 1.0 weight percent is a combination of 0.5 weight percent from random errors plus 0.5 weight percent as an estimation of systematic errors in. the average value.

The modified method of additions is not without its own limitations. In order to accurately determine the integrated intensity due to the amorphous component, an accurate measure of background intensity below the halo is required. Quartz powder ground from a single optical quality crystal to less than 40 microns was used to establish the background intensity under the halo as described earlier in the results.

In an effort to understand the affect of instrumental background correction on the amorphous content measurement several tests were performed. The first test consisted of trying different materials to establish the background intensity due, in part, to incoherent scattering from the cristobalite powder, as a single crystal of cristobalite was not available. Several materials, silicon powder (SRM 640a), a single crystal quartz plate, and ground quartz from an optical quality single crystal, were examined.

A well characterized material SRM 640 a, Silicon Powder, was used in the background approximation. This material was suggested because it is one of the elemental constituents of cristobalite and amorphous silica. The weight percent amorphous content of the cristobalite samples 10,69 , 187 and 187 (after acid treatment) as determined using Si (SRM 640a) for the background approximation are presented in Table 21 . The measured amorphous content was approximately double that found using quartz powder background data. The increase in measured amorphous content based upon a background simulated by silicon (SRM 640a) suggests that the scattering power of silicon powder is not sufficiently close to the scattering power of cristobalite. This difference in the measured amorphous content as determined with the ground quartz background approximation and the silicon background approximation is explained by the dependence of Compton modified scattering on atomic number. Compton modified or incoherent scattering is a component of the diffuse background which arises from the sample itself. Compton modified scattering becomes more intense with decreasing atomic number ${ }^{9}$ so the incoherent scattering from cristobalite or quartz $\mathrm{SiO}_{2}$ would be greater than the incoherent scattering from silicon. The amorphous intensity corrected for background by silicon appears greater than the amorphous intensity corrected for background by quartz, as indicated by the data in Tables 13 and 21. It appears that the influence of Compton modified scattering on the background intensity measured for cristobalite is great enough that silicon cannot be used to accurately model the cristobalite background.

Data from the single crystal quartz plate was collected on AM-1 and could be used for the background approximation for the amorphous areas in cristobalite. It was felt that the degree of perfection of the quartz plate could not adequately approximate the imperfections and possible 
Table 21. Amorphous Content of Cristobalite Determined by the Modified Method of Additions, Using Silicon (SRM 640a) for the Background Approximation

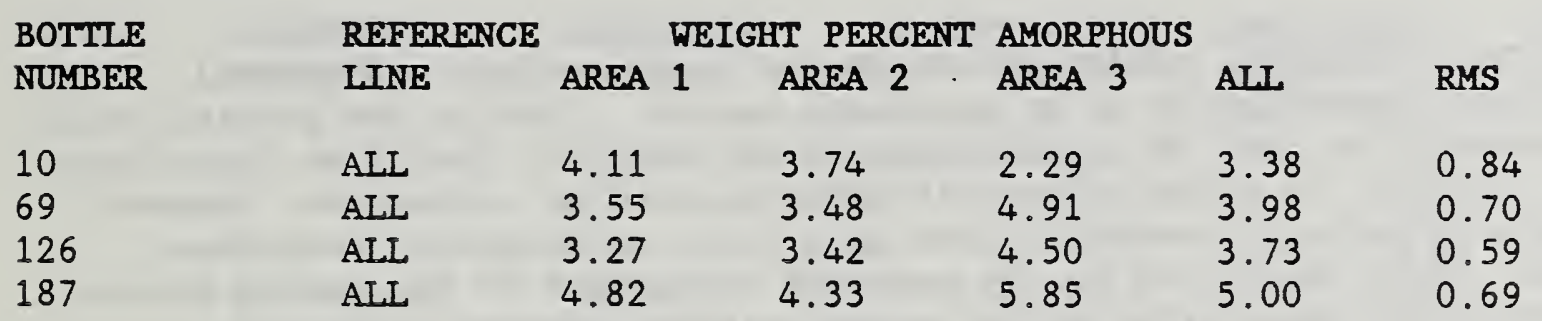


defects in the cristobalite crystals. Diffuse scattering from the sample itself can be broken into an incoherent component and a coherent component. The coherent component is dependent upon temperature-diffuse scattering and diffuse scattering due to imperfections in the crystals. Any kind of randomness or strain present in the crystals will cause coherent scattering which contributes to diffuse background ${ }^{24}$. The quartz plate showed a lower background intensity than the cristobalite. The larger background for the cristobalite powder was attributed to amorphous silica present in the cristobalite as well as the greater degree of perfection of the quartz plate.

Thus, a quartz powder ground from a single crystal of optical quality was investigated as an alternate source. Ideally the particle size of powders to be used for quantitative $x$-ray analysis should be less than $10 \mu \mathrm{m}$, in order to minimize particle effects such as extinction. However, extensive grinding of materials has been shown to introduce amorphous surface 20 which would add to the measured background of the quartz powder. This would introduce error in the weight percent amorphous content measurement of the cristobalite powder so a compromise was achieved. Single crystal quartz was ground such that 95 percent by mass of the particle were finer than $40 \mu \mathrm{m}, 60$ percent by mass less than $20 \mu \mathrm{m}$, and 20 percent by mass less than $5 \mu \mathrm{m}$. Based upon the investigation of various materials to approximate the background scattering from cristobalite, the quartz powder ground to less than $40 \mu \mathrm{m}$ was chosen as the best model of the incoherent scattering power of cristobalite.

The data of Table 13 seem to indicate that a small $2 \theta$ dependent systematic error in estimating the background is present. In an effort to pinpoint this systematic error it is important to understand the assumption used to correct for background. It was assumed that quartz ground from an optical grade single crystal would have the same incoherent scattering power as highly crystalline cristobalite because they have the same chemistry. The background beneath the amorphous areas was approximated by the background measured from the quartz powder. Thus a second investigation was undertaken to determine the sensitivity of the technique to changes in the measured background. The measured background, as determined from the diffraction pattern of ground quartz, was modified in the following ways. First the background approximation for each of the three selected amorphous regions was increased by the same factor. The counts per second of the measured background for all areas were increased by $2,3,5,10$ and 20 percent and also decreased by 20 percent. These various "backgrounds" were then used with the spike data files for samples 126 and 304, and the weight percent amorphous was determined for each sample using each modified background. This output appears in Table 22. Next, the intensity of the background in area 2 remained as measured and the background was modified to slope up or down through area 2 . This was accomplished by decreasing the counts per second in area 1 by 2,3 , 5 or 10 percent while at the same time increasing the counts per second of area 3 by $2,3,5$, or 10 percent respectively. To make the background slope downward through area 2 , the counts per second of area 1 were increased by $2,3,5$, or 10 percent while the counts per second of area 3 were decreased by $2,3,5$, or 10 percent, respectively. The amorphous content was then determined for samples 126 and 304 using these various background approximations, and is reported in Table 23. 
Table 22. Results of the Method of Additions for Determination of the Amorphous Silica Content in Cristobalite Samples 126 and 304 Using Modified Background Intensity

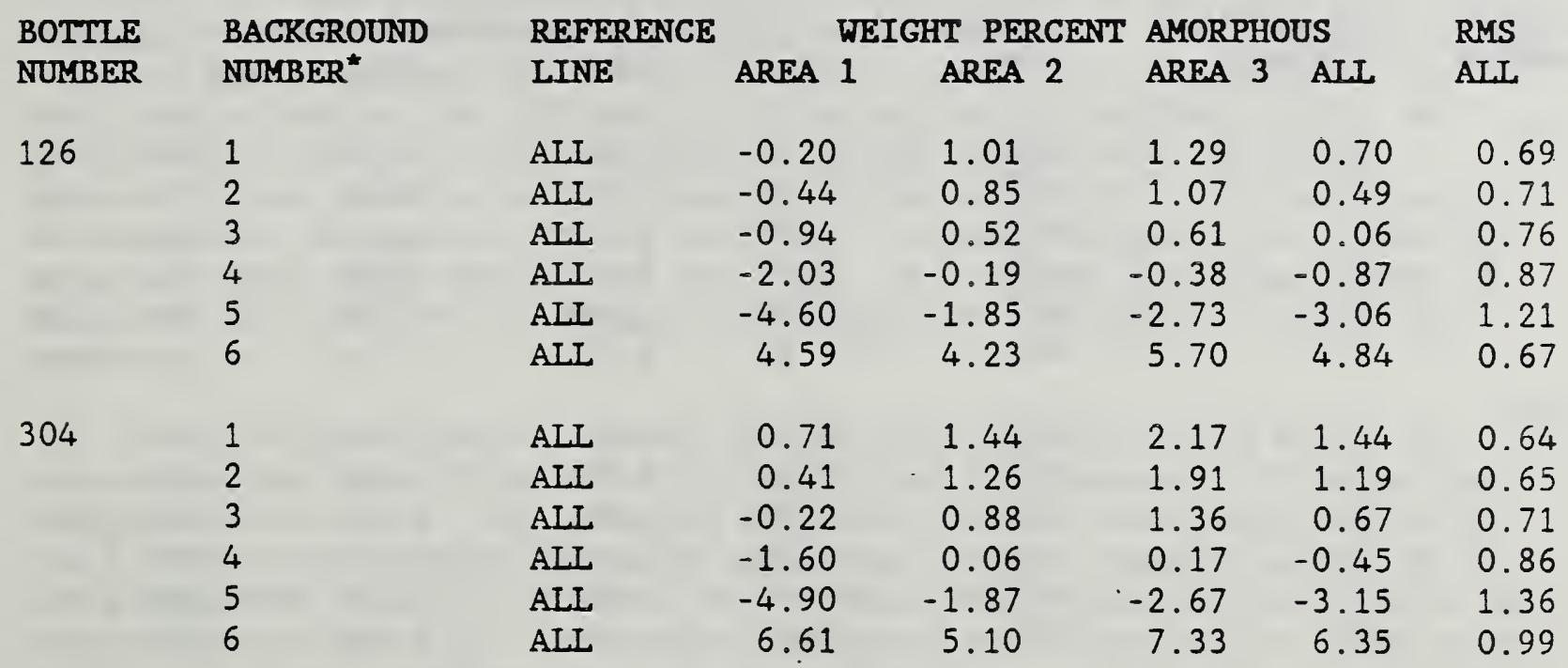

* Background numbers 1,2, 3, 4, 5 and 6 correspond to increasing the background intensity by $2,3,5,10$, and 20 percent and decreasing the background intensity by 20 percent, respectively. 
Table 23. Results of the Method of Additions for Determination of the Amorphous Silica Content in Cristobalite Samples 126 and 304 Using Modified Background Intensity

\begin{tabular}{|c|c|c|c|c|c|c|c|}
\hline \multirow{2}{*}{$\begin{array}{l}\text { BOTTLE } \\
\text { NOMBER }\end{array}$} & \multirow{2}{*}{$\begin{array}{l}\text { BACKGROUND } \\
\text { NUMBER* }^{*}\end{array}$} & \multicolumn{2}{|c|}{ REFERENCE } & WEIGHT PERCENT & \multicolumn{2}{|c|}{ AMORPHOUS } & \multirow{2}{*}{$\begin{array}{l}\text { RMS } \\
\text { ALL }\end{array}$} \\
\hline & & LINE & AREA 1 & AREA 2 & AREA 3 & ALL & \\
\hline \multirow[t]{6}{*}{126} & 1 & ALL & -0.20 & 1.32 & 2.12 & 1.08 & 1.02 \\
\hline & 2 & ALL & -0.44 & 1.32 & 2.32 & 1.06 & 1.21 \\
\hline & 3 & ALL & 1.33 & 1.32 & 0.61 & 1.09 & 0.36 \\
\hline & 4 & ALI & 2.45 & 1.32 & -0.38 & 1.13 & $1: 24$ \\
\hline & 5 & ALI & -0.94 & 1.32 & 2.69 & 1.02 & 1.59 \\
\hline & 6 & ALI & -2.03 & 1.32 & 3.73 & 1.01 & 2.50 \\
\hline \multirow[t]{6}{*}{304} & 1 & AIL & 0.71 & 1.80 & 3.15 & 1.89 & 1.06 \\
\hline & 2 & ALL & 0.41 & 1.80 & 3.38 & 1.86 & 1.29 \\
\hline & 3 & ALL & 2.62 & 1.80 & 1.36 & 1.92 & 0.56 \\
\hline & 4 & ALI & 4.01 & 1.80 & 0.17 & 1.99 & 1.67 \\
\hline & 5 & ALL & -0.22 & 1.80 & 3.83 & 1.80 & 1.76 \\
\hline & 6 & ALI & -1.60 & 1.80 & 5.05 & 1.75 & 2.88 \\
\hline
\end{tabular}

* Background numbers 1,2,3 and 4 correspond to sloping the background upward through area 2 by decreasing the intensity of area 1 by $2,3,5$ or 10 percent while simultaneously increasing the intensity of area 3 by 2,3,5 or 10 percent, respectively. Background numbers 5 and 6 correspond to sloping the background downward through area 2 by increasing the intensity of area 1 by 5 or 10 percent while decreasing the intensity of area 3 by 5 or 10 percent. 
An increase of the entire background by 10 or 20 percent results in a negative determination of the amorphous content for both samples. This is indicative of a background approximation which is greater than the actual background of the cristobalite sample. An increase of the entire background by 2,3 and 5 percent respectively results in a decrease in the amount of amorphous content with increasing background intensity, as expected. A decrease of the entire background intensity by 20 percent results in an amorphous content as great as four times the amount reported in Table 13. The regression analysis is still able to fit straight lines through this data with very high correlation factors. What changes is the slope of the lines and the $x$ - intercepts. Thus it is important to note that simply judging the linearity of the regression analys is gives no indication of how well the background intensity has been corrected.

However, these results help to determine the sensitivity of the technique to changes in background as the amorphous content changes appropriately depending upon which background is used. We conclude that the method of additions is sensitive to changes in background intensity as small as 2 percent.

The results of Table 23 seem to indicate that the trend which is present in the data of Table 13 is unaffected by changes in slope of the background intensity. By changing the slope of the background intensity the area-by-area determination of amorphous content remains sensitive to the background intensity however the overall determination lies within the expected accuracy of the technique. Changing the slope of the background does change the amorphous content determined for each area, but the change in area 1 is the same magnitude but of opposite sign of the change in area 3 so in effect the change in area 1 is offset by the change in area 3 and the resultant weight percent amorphous lies within the expected error of measurement. The data indicate that the amorphous determination is sensitive to changes in slope of the background. However, by averaging the determination from each area to get a resultant measurement of amorphous content the effects are averaged out and the final weight percent amorphous remains insensitive to the change. For changes in background intensity of 2 percent the average change in amorphous content was 0.23 weight percent. We take this (or two times this) as the level of residual systematic errors due to background.

One suggested explanation of the trend evident in the data of Table 13 is that the areas chosen as regions of the amorphous halo were not free from interference with tails of the Bragg peaks. Specifically, the increased amorphous intensity of area 3 may be due to the additional intensity of the tails of the (110) and (111) reflections. The regions of amorphous intensity were selected carefully from the strip chart pattern of a 50:50 mixture of cristobalite with fused quartz collected on AM-1, Figure 9. However, a small change in the alignment of the instrument or the fact that AM-2 was used for the actual amorphous determination may have been enough to shift the peaks slightly as well as the region of the tail into the designated amorphous region. Although plots of the data for sample 211, Figure 10, clearly indicate that the reference peaks were not shifted into the amorphous areas, the fact that the (110) and (111) peaks were not collected as reference lines does not allow adequate information as to whether or not the tails of these peaks interfered with area 3 . Thus data 


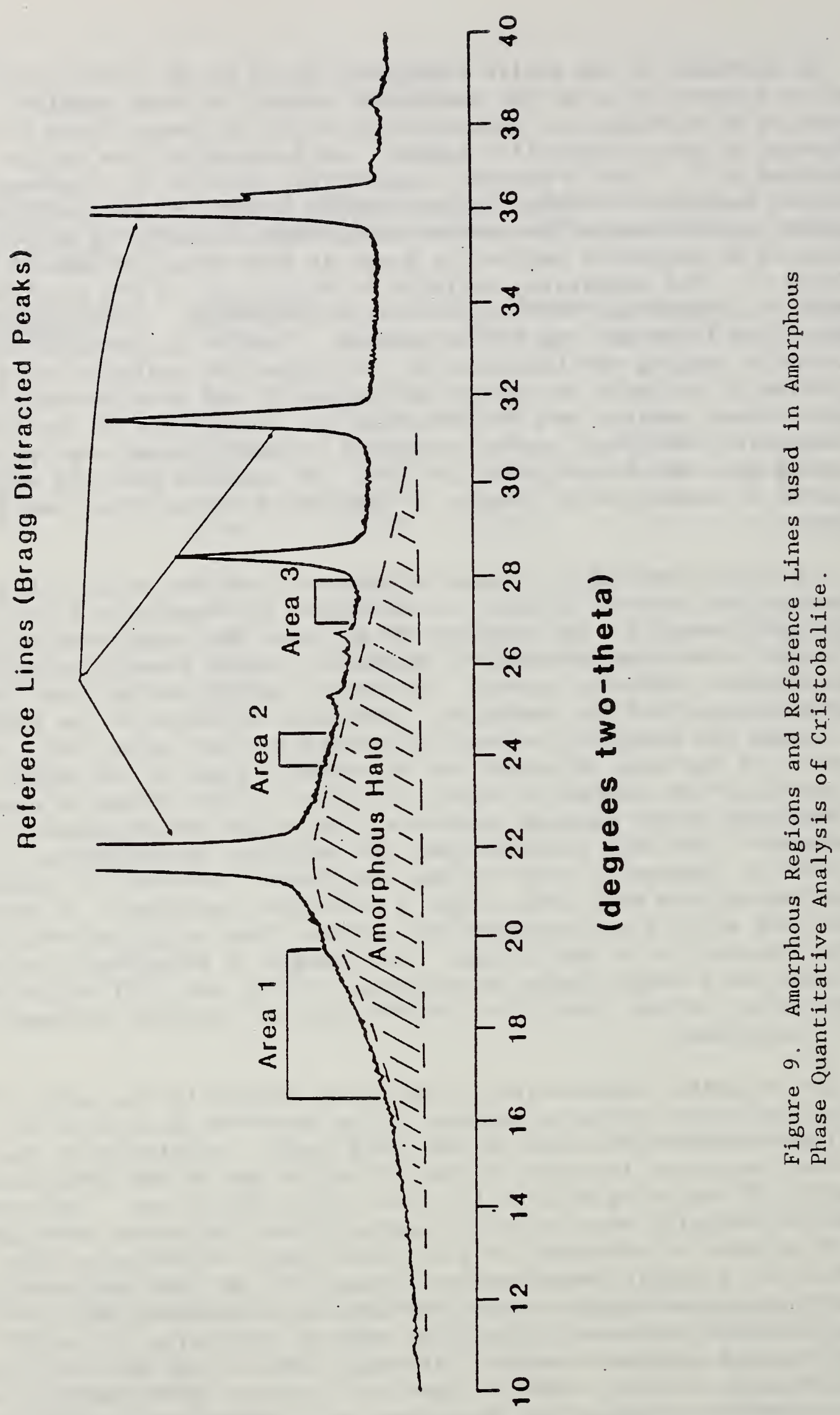



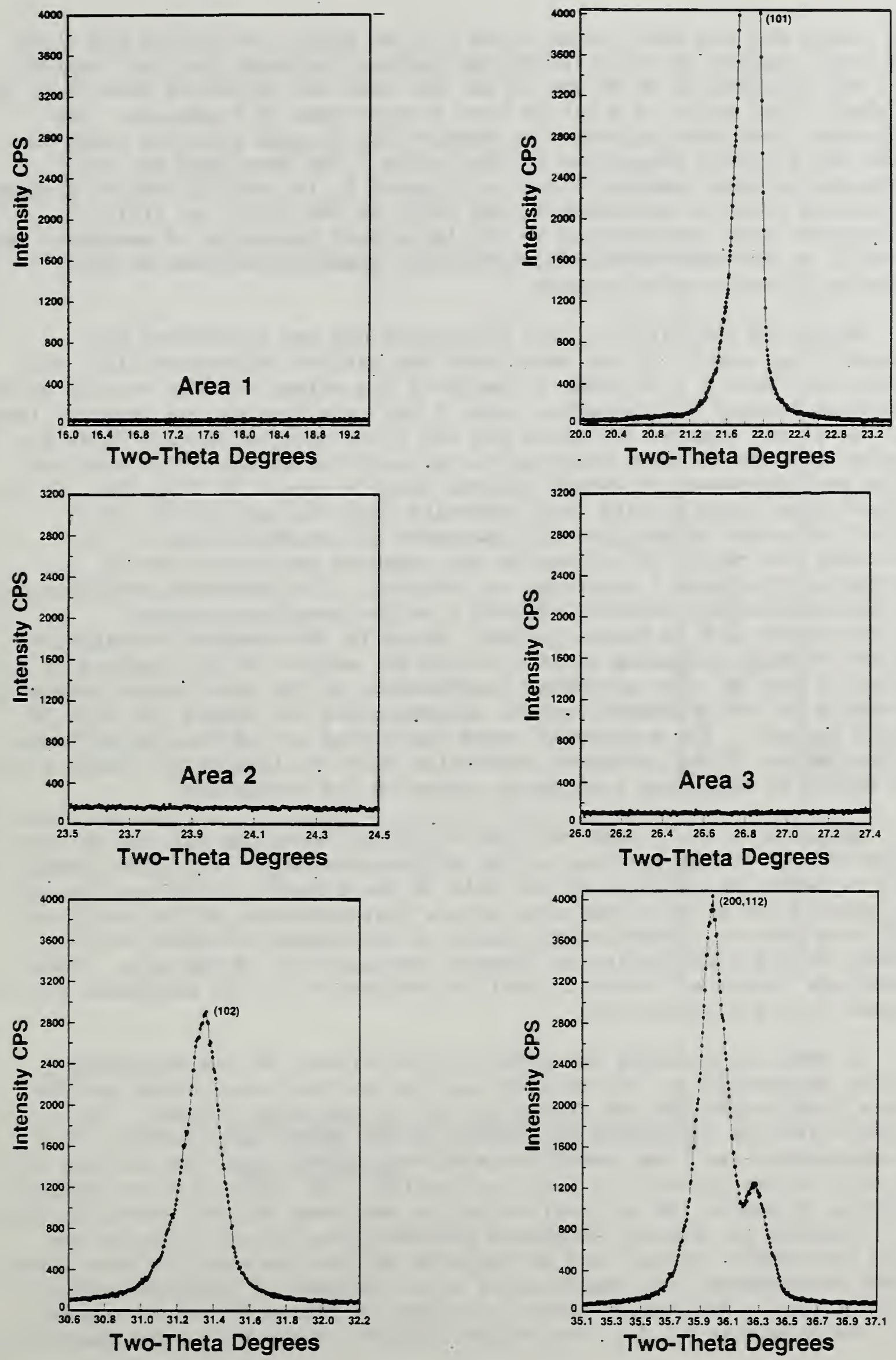

Figure 10. Measured Intensities of Amorphous Areas and Reference Lines for Sample 211. 
for sample 211 was recollected on AM-1 in an effort to isolate the (110) and (111) regions of the cristobalite pattern including the tail region. AM- 1 was operated at $40 \mathrm{kv}$ and $40 \mathrm{ma}$, and data was collected from 15 to $35^{\circ}$ $2 \theta$ with a step width of $0.01^{\circ} 2 \theta$ with a count time of 2 seconds. Two reference lines were collected so that shifts in peak position could be noted and all data normalized to that value. The data from the two measurements were compared visually (Figures 9, 10, and 11) and on a counts per second scale to determine if the tails of the (110) and (111) reflections were contributing to the integrated intensity of amorphous area 3 and if so how much of an effect did this contribution have on the amorphous content determination.

While the tail of the (110) reflection did not contribute any intensity to area 3 , it was noted that the tail of reflection (111) did extend into area 3 . In order to estimate the effect of this overlap on the amorphous content determination, area 3 was redefined as the interval from 26.0 to 27.035 degrees two-theta and the $x$-ray data collection files for samples 211 and 304 were modified to reflect this change. The modified files were processed by Q85AMR and the results appear in Table 24 . It is evident from these results that intensity from the tail of the (111) reflection added to the intensity measured in amorphous area 3 . By narrowing the region of collection the measured amorphous content determined from area 3 decreases as expected. The estimated contribution of the uncorrected intensity of area 3 on the amorphous content determination is 0.24 weight percent, which is the standard deviation of the two average amorphous content values for sample 304 as reported in Tables 13 and 24. The estimated contribution of the uncorrected intensity of area 3 on the amorphous content determination for sample 211 is 0.29 weight percent. The systematic trend identified in the results of Table 13 is the result of the incorrect assumption that the intensity of area 3 is due solely to amorphous scattering corrected for background.

Nakamura et al. ${ }^{8}$, observed that different amorphous silicas do show slight shifts in the position of the diffraction halo. An effort should be made to match the position of the halo of the diluent to the position of the halo in the original material before implementation of the modified additions method. Unfortunately there is not enough amorphous silica present in the cristobalite to identify the position of the halo. Fused quartz was chosen as the most likely approximation of any amorphous silica present in the cristobalite.

In order to evaluate the effect of the diluent on the amorphous content determination, the spiking analysis was performed using another sample from bottle 304 and silica gel as the amorphous diluent. To properly isolate the effect of diluent on the amorphous content determination area 3 was redefined such that it was free from overlap with the tail of the crystalline (111) reflection. The results of the spiking analysis of sample 304 with silica gel as amorphous diluent appear in Table 25. Although the average amorphous determination is very close to the value for sample 304 reported in Table 24 (within the expected uncertainty of the measurement) the area-by-area determinations of amorphous weight fraction show a systematic trend. The data in Tables 24 and 25 suggest that the structure of the fused quartz diluent is a better approximation of 


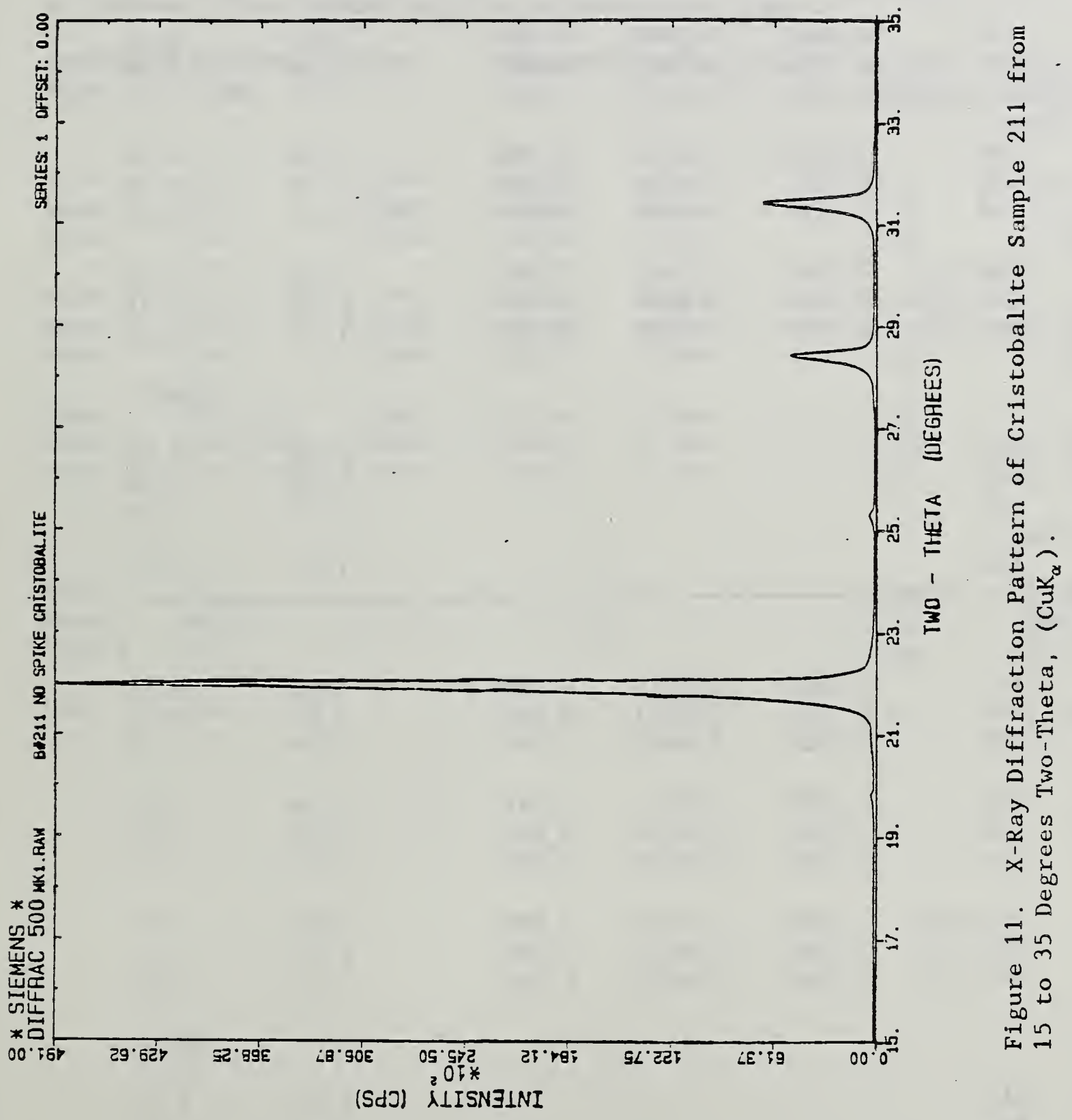


Table 24. Results of the Modified Method of Additions for Determination of the Amorphous Silica Content in Cristobalite Samples 211 and 304 using Redefined Area 3

\section{AMORPHOUS REFERENCE SLOPE \\ AREA \\ LTNE}

INTERCEPT CORRELATION

0.2442

0.0852

0.0565

0.0048

0.0016

0.998

0.0010

0.999

0.999

2. 2410

0.7821

0.5189

0.0447

0.0150

0.998

0.0090

0.999

0.999

0.0261

0.0088

0.0053

0.998

0.999

0.999

0.4656

0.3089

0.3089

WEIGHT

PERCENT
LEAST SQUARES ESD

Area $2 \quad 200,112$

1.97

0.44

1.90

0.24

1.72

0.26

Area $3 \quad 200,112$

0.0053

2.00

0.47

1.92

0.25

1.74

0.27

1.96

0.45

1.88

0.25

1.71

0.27

RMS

\begin{tabular}{llllr} 
Area & 1 & ALL & 1.98 & 0.02 \\
Area & 2 & ALL & 1.90 & 0.02 \\
Area 2 & ALL & 1.73 & 0.02 \\
ALI & & ALL & 1.87 & 0.11 \\
\hline
\end{tabular}

SAMPLE 304

\begin{tabular}{|c|c|c|c|c|c|c|}
\hline Area 1 & 101 & 0.2280 & 0.0031 & 0.999 & 1.36 & 0.45 \\
\hline Area 2 & 101 & 0.0797 & 0.0015 & 0.999 & 1.87 & 0.39 \\
\hline Area 3 & 101 & 0.0526 & 0.0007 & 0.999 & 1.29 & 0.28 \\
\hline Area 1 & 102 & 2.1007 & 0.0271 & 0.998 & 1.29 & 0.49 \\
\hline Area 2 & 102 & 0.7344 & 0.0132 & 0.999 & 1.79 & 0.42 \\
\hline Area 3 & 102 & 0.4843 & 0.0059 & 0.999 & 1.23 & 0.31 \\
\hline Area 1 & 200,112 & 1.2439 & 0.0152 & 0.999 & 1.22 & 0.41 \\
\hline Area 2 & 200,112 & 0.4349 & 0.0075 & 0.999 & 1.72 & 0.35 \\
\hline Area 3 & 200,112 & 0.2868 & 0.0033 & 1.000 & 1.16 & 0.25 \\
\hline
\end{tabular}

RMS

Area 1 ALL

$\begin{array}{ll}1.29 & 0.07\end{array}$

Area 2 ALL

1.80

0.07

Area 3 ALL

1.23

0.07

ALL

ALI

1.44

0.28 
Table 25. Results of the Modified Method of Additions for Determination of the Amorphous Silica Content in Cristobalite Sample 304, Using Silica Gel as Diluent, Four.Spiked Samples and Redefined Area 3

$\begin{array}{lllll}\text { AMORPHOUS } & \text { REFERENCE SLOPE } & \text { INTERCEPT CORRELATION } & \text { WEIGHT } & \text { LEAST } \\ \text { AREA } & \text { LINE } & & \text { PERCENT } & \begin{array}{l}\text { SQUARES } \\ \text { ESD }\end{array}\end{array}$

\begin{tabular}{|c|c|c|c|c|c|c|}
\hline Area & 101 & 0.1893 & 0.0038 & 0.998 & 2.01 & 0.53 \\
\hline Area 2 & 101 & 0.0980 & 0.0017 & 0.999 & 1.74 & 0.39 \\
\hline Area & 101 & 0.0758 & 0.0009 & 0.999 & 1.22 & 0.38 \\
\hline Area 1 & 102 & 1.7741 & 0.0313 & 0.998 & 1.76 & 0.59 \\
\hline Area & 102 & 0.9180 & 0.0138 & 0.999 & 1.50 & 0.36 \\
\hline Area & 102 & 0.7099 & 0.0071 & 0.999 & 1.00 & 0.35 \\
\hline Area & 200,112 & 1.0481 & 0.0188 & 0.998 & 1.80 & 0.5 \\
\hline Area 2 & 200,112 & 0.5423 & 0.0083 & 0.999 & 1.53 & 0.34 \\
\hline Area 3 & 200,112 & 0.4194 & 0.0043 & 0.999 & 1.03 & 0.33 \\
\hline
\end{tabular}

\section{RMS}

Area 1 ALL

1.86

0.13

Area 2 ALL

1.59

0.13

Area 3 ALL

1.08

0.12

ALL

ALL

1.51

0.36 
the structure of the amorphous silica present in the cristobalite than the silica gel.

Another method employed to check the modified additions method was acid washing of the cristobalite powder as outlined by Altree-Williams et $\mathrm{al}^{20}$. Two samples of cristobalite were washed with hot phosphoric acid in an attempt to dissolve any amorphous silica present in the powder. Samples 126 and 187 were treated in this way, then the RIR constant and amorphous content were remeasured using the methods outlined previously. The results of Table 14 show that the RIR's and weight percent amorphous content actually increased for the acid washed samples. Careful inspection of the data for both bottles indicates that the values of RIR and weight percent amorphous content of the acid washed samples lie within the predicted uncertainty of the measurements. The change in RIR is less likely to indicate a change in the actual amorphous content of the sample because of the factors previously mentioned which limit its accuracy. For sample 126 the reported weight percent amorphous in Table 13 is 1.10 weight percent amorphous and the reported weight percent amorphous of the acid washed samples as reported in Table 14 is 1.15 weight percent; a difference of 0.05 weight percent amorphous. The expected precision of this technique at this level of amorphous content is about 0.50 weight percent amorphous. The results indicate that the acid wash did not dissolve any amorphous silica. It is plausible that the amorphous material is located at or near grain boundaries, instead of at free surfaces which would result from grinding of the material.

\section{CONCLUSION}

The results of the chemical analysis of the lot of cristobalite, shown in Table 1, show a minimum of trace impurities. By $x$-ray standards the cristobalite was "phase pure" and suitable for quantitative analysis of the amorphous silica content.

Based upon the particle size analysis (Table 2), all bottles appear to have a uniform particle size distribution. From the lattice parameter studies, there is some probability of bottle to bottle variability as indicated by the larger SD value for the 16 bottles (Table 5) compared with the SD value observed for measurement reproducibility (Tables 6-9). The possible variability, however, is quite small and should have no observable effect on the certified percent crystalline content. This is confirmed in the $I^{R \theta 1}$ results reported in Table 10 ; no bottle is judged to be significantly different than any other.

Fundamentally, the RIR constant is an indicator of crystallinity. However, limited choice of standard material as well as the effects of extinction and absorption on the RIR measurement, prevented the use of the RIR constant to calculate the amorphous content of the cristobalite. A change in amorphous content as measured by the method of additions should correspond to a change in RIR. At this level of detection ( 0 - 5 weight percent amorphous) the RIR constant was relatively insensitive to small changes in the weight percent amorphous present in the cristobalite.

The method of additions was modified to allow direct determination of the amorphous silica content present in synthetic cristobalite powder. The 
modification was accomplished by using fused quartz as the diluent and measuring the background corrected integrated intensity of amorphous scattering.

The sensitivity of the technique to changes in the approximate background intensity was evaluated. The method of additions was sensitive to variations in background intensity as small as 2 percent.

Three areas of the amorphous halo and three cristobalite reference lines not interfered with by other Bragg diffraction peaks were chosen to give nine independent measures of the amorphous silica content. Three sources of error were identified as possible causes of the systematic trend apparent in Table 13. First, the condition that all areas be free of interference with Bragg diffraction peaks was not completely met. The tail of the (111) reflection added intensity to the measured amorphous intensity of area 3. This caused the determination of amorphous content using area 3 to be consistently higher than that determined with the other areas. Another source of error arises from the inability to detect the exact position of the amorphous halo in the undiluted cristobalite sample. The mismatch in position of the amorphous halo between the diluent and the amorphous silica present in the cristobalite contributes to this error. The data indicate that the fused quartz chosen for this analysis was the best approximation of the amorphous silica present in the cristobalite as compared to the silica gel. Finally, the effect of using ground quartz powder to simulate the background intensity under the amorphous halo in cristobalite was examined as a source of error in the measurement. The estimated contribution of these sources of error to uncertainty in the measurement was 0.5 weight percent amorphous content.

The average weight percent amorphous silica content in the cristobalite as determined with this method was 2 weight percent with a standard deviation of 1.0 weight percent. This standard deviation was based upon an estimated 0.5 weight percent contribution due to random errors plus a 0.5 weight percent estimation of the systematic errors in the average value. 


\section{REFERENCES}

1. "Free Silica (Quartz, Cristobalite, Tridymite) in Airborne Dust," NIOSH Manual of Analytical Methods, Volume 5, pp. 259-1-259-13, may be ordered from the Superintendent of Documents, U.S. Government Printing Office, Washington, D.C. 20402 or the National Information Service, Springfield, VA 22161.

2. Frank H. Chung, "Quantitative Interpretation of X-Ray Diffraction Patterns of Mixtures. .I. Matrix-Flushing Method for Quantitative Multicomponent Analysis," J.Appl. Cryst., 7, 519-525, 1974.

3. Torben Knudsen, "X-Ray Methods for the Determination of the Amounts of Glass Phase in Mullite Refractory Grog," X-Ray Spectrometry, 5, 197-199, 1976.

4. S.M. Ohlberg and D.W. Strickler, "Determination of Percent Crystallinity of Partly Devitrified Glass by X-ray Diffraction, " Journal of the American Ceramic Society, 45, 170-171, 1962.

5. L. Cervinka and J. Dusil, "Determination of Crystallinity in Crystallized Glasses by X-Ray Diffraction," J. Non-Cryst. Solids, 21, 125$136,1976$.

6. Kazuo Torii, Masami Hotta and Makotta Asaka, "Quantitative Estimation of Mordenite and Clinoptilolite in Sedimentary Rocks (I)," J. Japan. Assoc. Min. Petr. Econ. Geol, 74, 251-264, 1979.

7. National Bureau of Standards Certificate of Analysis, Standard Reference Material 1878, Respirable Alpha Quartz (Quantitative X-Ray Powder Diffraction Standard).

8. Toshihiro Nakamura, Katsumi Sameshima, Kiyoyuki Okunaga, Yoshitaka Sugiura and Jun Sato, "Determination of Amorphous Phase in Quartz Powder by X-Ray Powder Diffractometry and Effect of Amorphous Phase on Relative Intensity Ratio of Quartz," submitted to Powder Diffraction.

9. Harold P. Klug and Leroy E. Alexander, X-Ray Diffraction Procedures for Polycrystalline and Amorphous Materials, John Wiley and Sons, New York, 1974, pp. 239-241, 366, 541-543.

10. Robert L. Snyder and Camden R. Hubbard, "NBS*QUANT 84: A System for Quantitative Analysis by Automated X-Ray Powder Diffraction," available from authors.

11. Camden R. Hubbard and Robert L. Snyder, "RIR - Measurement and Use in Quantitative X-Ray Diffraction," submitted to Powder Diffraction, 1987.

12. Howard F. McMurdie, Marlene C. Morris, Eloise H. Evans, Boris Paretzkin, Winnie Wong- $\mathrm{Ng}$ and Camden $\mathrm{R}$. Hubbard, "Methods of Producing Standard X-Ray Diffraction Patterns, " Powder Diffraction, 1, No. 1, 40-43, March 1986. 
13. R.L. Snyder, C.R. Hubbard and N.C. Panagiotopoulos, "A Second Generation Automated Powder Diffraction Control System," Advances in X-RAy Analysis, 25, 245-260, 1982.

14. N.P. Pyrros and C.R. Hubbard, "Powder-Pattern: A System of Programs for Processing and Interpreting Powder Diffraction Data," Advances in X-Ray Analysis, 26, 63, 1983.

15. D.E. Appleman and H.T. Evans, Jr., Report \#PB216188, U.S. Dept. of Commerce, National Technical Information Service, 5285 Port Royal Rd., Springfield, VA 22151.

16. Deane K. Smith, Monte C. Nichols, and Michael E. Zolensky, "POWD10: A Fortran IV Program for Calculating X-ray Powder Diffraction Patterns Version 10," available from authors.

17. W.A. Dollase, "Reinvestigation of the Structure of Low Cristobalite," Zeitschrift fur Kristallographie, 121, $369-377,1965$.

18. Donald R. Peacor, "High-Temperature Single-Crystal Study of the Cristobalite Inversion," Zeitschrift fur Kristallographie, 138, 274 - 298, 1973.

19. Private communication, Lois Johnson, Rutgers - The State University of NJ, Dept. of Ceramics, Piscataway, NJ.

20. Stephen Altree-Williams, John G. Byrnes and Bernard Jordan, "Amorphous Surface and Quantitative X-Ray Powder Diffractometry, " Analyst, 106, 69 $75,1981$.

21. James P. Cline and Robert L. Snyder, "The Effects of Extinction on XRay Powder Diffraction Intensities," Advances in X-Ray Analysis, 30, 447$456,1987$.

22. Larry W. Finger and Robert M. Hazen, "Crystal Structure and Isothermal Compression of $\mathrm{Fe}_{2} \mathrm{O}_{3}, \mathrm{Cr}_{2} \mathrm{O}_{3}$, and $\mathrm{V}_{2} \mathrm{O}_{3}$ to $50 \mathrm{kbars,"} \mathrm{J.Appl.} \mathrm{Phys.,} \mathrm{51(10),}$ $5362,1980$.

23. Howard F. McMurdie, Marlene C. Morris, Eloise H. Evans, Boris Paretzkin, Winnie Wong-Ng and Yuming Zhang, "Standard X-Ray Diffraction Powder Patterns from the JCPDS Research Associateship," Powder Diffraction, 2(1), 45, 1987.

24. B.D. Cullity, Elements of X-Ray Diffraction, Addison-Wesley Publishing Company, Inc., 1978. 


\begin{tabular}{|c|c|c|}
\hline U.S. DEPT. OF COMM. & 1. PUBLICATION OR & 2. Performing Organ. Report $\mathrm{No}^{3}$ 3. Publication Date \\
\hline $\begin{array}{l}\text { BIBLIOGRAPHIC DATA } \\
\text { BHEET (See instructions) }\end{array}$ & $\begin{array}{l}\text { REPORT NO. } \\
\text { NBS IR } 88-3742\end{array}$ & APRIL 198 \\
\hline
\end{tabular}

4. TITLE AND SUBTITLE

CERTIFICATION OF SRM 1879 RESPIRABLE CRISTOBALITE AS A QUANTITATIVE X-RAY

DIFFRACTION SRM

5. $A U T H O R(S)$

Madeline A. Kuchinski and Camden R. Hubbard

\begin{tabular}{|l|l|}
\hline 6. PERFORMING ORGANIZATION (If joint or other than NBS. see in structions) & 7. Contract Grant No.
\end{tabular}

NATIONAL BUREAU OF STANDARDS

U.S. DEPARTMENT OF COMMERCE

GATTHERSBURG, MD 20899

9. SPONSORING ORGANIZATION NAME AND COMPLETE ADDRESS (Street, City, State, ZIP)

NBS

10. SUPPLEMENTARY NOTES

Document describes a computer program: SF-185, FIPS Software Summary, is attached.

11. ABSTRACT (A 200-word or less factual summary of most significant information. If document includes a significant bibliography or literoture survey, mention it here)

Well characterized, highly crystalline standard materials are essential for accurate quantitative $x$-ray powder diffraction work. Synthetic cristobalite powdef was certified as a Standard Reference Material for quantitative x-ray diffraction analysis of cristobalite content. Qualitative analyses by Guinier de Wolff camera and focusing diffractometer of the bulk powder indicated only crystalline a c cristobalite. Elemental analysis revealed only trace impurities; the largest being Al at 1000 ppm. Quantitative determination of the crystallinity of the material was performed. A quantitative technique which employs a modified method of additions to directly analyze for low amorphous content in crystalline matrices was developed and tested. Known amounts of amorphous material are added to the starting powder ("spiking"). The method uses the ratio of a measure of the intensity of the amorphous phase to the intensity of a reference line from a crystalline phase. A critical step of the method is to correctly establish the background intensity. A completely crystalline material of similar scattering power was used to establish background intensity. An amorphous phase close in composition to the amorphous phase existing in the analyte was used for spiking. The certified crystalline purity of the cristobalite SRM 1879 was 98.0 weight percent crystalline cristobalite. The estimated standard deviation was 1.0 weight percent arising from a standard deviation of 0.5 weight percent due to random and inhomogeneity errors plus an estimated likely systematic error of 0.5 weight percent. 12. KEY WORDS (Six to twelve entries; alphabetical order; capitalize only proper names; and separate key words by semicolons) amorphous content; cristobalite; crystallinity; standard reference material; quantitative analysis; $x$-ray powder diffraction

13. AVAILABILITY

X Unlimited

For Official Distribution. Do Not Release to NTIS

Order From SuDerintendent of Documents, U.S. Government Printing Office, Washington. D.C. 20402.

X] Order From National Technical Information Service (NTIS), Springfield, VA. 2216I
14. NO. OF PRINTED PAGES

64

15. Price

$\$ 13.95$ 